\title{
An innovative investigation on chip formation mechanisms in micro-milling using natural diamond and tungsten carbide tools
}

\author{
Zhichao Niu, Feifei Jiao and Kai Cheng \\ College of Engineering, Design and Physical Sciences, Brunel University London \\ Uxbridge UB8 3PH, $U K$
}

Emails: zhichao.niu@brunel.ac.uk; kai.cheng@brunel.ac.uk

\begin{abstract}
This paper presents an analytical approach to investigating the chip formation process in micro-milling aluminum 6082-T6 particularly by using natural diamond and tungsten carbide tools. Through well-designed micro-milling experiments, a comparative study is conducted by utilizing a natural diamond tool with the perfectly sharpened cutting edge and a tungsten carbide tool with the rounded cutting edge respectively. Cutting forces are recorded and analyzed as one of main process indicators. The chip morphology and micro milling processes are analyzed in correlation with cutting force variations in the processes. The size effect, minimum chip thickness and their integral effect are quantitatively assessed against the chip formation process. Research results show that the chips formed during the consecutive revolutions are affected jointly by the cutting tool/workpiece material pair and the cutting edge radius in using tungsten carbide tools; whereas the chips formed by using diamond tools are intact and separate. Furthermore, the cutting force and thrust force are of the same order due to the cutting edge radius cannot be ignored. For using a natural diamond tool with the sharp cutting edge, the resultant cutting force is usually two times higher than the thrust force.
\end{abstract}

Keywords: Chip formation, micro milling, minimum chip thickness, size effect, natural diamond tool, tungsten carbide tool 


\section{Introduction}

Since late 1990s, there has been an increasing demand for compact, integrated and miniature products for use in our daily life as well as for industrial applications. Many miniature and micro components or products are made from aluminum alloys because of their engineering material properties and wide applications particularly in aviation and aerospace industries ${ }^{[1]}$. The chip formation process in micro milling homogeneous aluminum material is quite different from that in the conventional milling process. The most prominent phenomenon is the size effect, which is understood as the increases of the specific cutting force with decreases in cutting thickness. Due to the existence of the non-negligible cutting edge radius, the cutting tool may keep ploughing the workpiece surface and consequently there is no chip formation in micro milling with a very small depth of cut. In this scenario, the workpiece material undergoes pure elastic deformation when the cutting tool goes through and then the workpiece material recovers to the original height or less. With the continuous increase of the cutting depth, the material plastically deforms partially and the chips start to form only if the uncut chip thickness approaches a certain threshold. Therefore, the chips can be formed and removed only when the depth of cut exceeds the minimum chip thickness. This is normally known as the minimum chip thickness effect $^{[2-7]}$. This effect distinguishes the micro milling substantially from the macro milling. The quantitative identification of the minimum chip thickness is a critical issue in micro milling, which has been investigated by many researchers ${ }^{[8-9]}$. It is widely accepted that the chip formation in micro cutting is separated into two regimes: ploughing dominant regime and shearing dominant regime. The scientific and systematic understanding of the chip formation process in micro cutting, especially in micro milling, is essential and much needed particularly against the increasingly stringent requirement for industrial scale micro milling operations.

The research presented in this paper attempts to investigate an industrial feasible analytical approach for scientific understanding the chip formation process in micro milling and the associated technological perspectives in machining applications. The innovative investigation on chip formation mechanisms by using natural diamond and tungsten 
carbide micro milling tools is carried out through theoretical exploration, modelling and analysis of the micro cutting mechanics particularly the micro milling forces modelling and analysis. The chip formation and micro cutting forces are further evaluated and validated with well-designed experimental trials.

\section{Analysis and insight into chip formation mechanism in micro milling}

In micro milling aluminum 6082-T6 by using nature diamond tool and tungsten carbide tool, cutting process behaviors and cutting performances including the cutting mechanics, chip formation, surface generation and tool wear can be analyzed from the cutting force even for a complex cutting process with various process variables ${ }^{[10]}$. Due to the cutting force can be achieved from modelling technique and experiments, the cutting mechanics particularly for the chip formation mechanics can be accurately analyzed afterwards. According to the measured cutting force and thrust force data in micro milling process, the chip formation mechanisms such as the minimum chip thickness and chip breakage can be easily predicted in conventional cutting process. However, previous research and experiments show that cutting forces in micromachining are quite small down to the $0.1 \sim 1 \mathrm{~N}$ scale in magnitude. The direct usage of absolute cutting force imposes the technical challenge in accurate measurement of the micro cutting forces particularly in the cutting process. Thus, the chip formation mechanisms cannot be predicted accurately based on the absolute cutting force values. Furthermore, it is essential in developing the cutting force modelling for bridging the gaps between understanding the micro cutting mechanics and the process optimization and cutting performance enhancement. Therefore, an innovative cutting force modelling is proposed to provide insightful quantitative analysis into micro milling mechanics and the process, which is further presented in details below.

Since the micro milling force is at $0.1-1 \mathrm{~N}$ scale, the cutting force at the unit area is presented as the specific cutting force so as to better illustrate the underlying chip formation mechanisms in relation to micro cutting forces. The specific cutting force that 
acts at the contact area through the tool tip and workpiece interaction is considered as the effective force, which leads to the chip formation and the resultant surface generation. In addition, the specific cutting force at the unit area can be closely linked with the material Young's modulus, i.e. the ultimate strength of the workpiece material, which can provide micro mechanics insights on the chip formation and breakage, surface generation and even the tool wear at both rake and flank surfaces of a milling tool. The specific cutting force at a unit area overcoming the ultimate strength in the chip formation is expressed in Equation (1):

$$
\begin{aligned}
& F_{S x}(t, k)=\frac{F_{x}(t)}{S} \\
& F_{S y}(t, k)=\frac{F_{y}(t)}{S}
\end{aligned}
$$

Where, $F_{x}(t), F_{y}(t)$ are the orthogonal cutting forces in chip formation process. The integrated cutting forces over the range of engagement of each cutting flute against the workpiece material are illustrated in Equation (2) and Equation (3):

When the cutting chip thickness is smaller than minimum chip thickness,

$$
\begin{aligned}
& F_{x}(t)=R \cot \beta \int_{\theta_{e n}}^{\theta_{e x}}\left(K_{r p} A_{p} \sin \theta+K_{r e} \sin \theta+K_{t p} A_{p} \cos \theta+K_{t e} \cos \theta\right) d \theta \\
& F_{y}(t)=R \cot \beta \int_{\theta_{e n}}^{\theta_{e x}}\left(K_{r p} A_{p} \cos \theta+K_{r e} \cos \theta-K_{t p} A_{p} \sin \theta-K_{t e} \sin \theta\right) d \theta
\end{aligned}
$$

When the cutting chip thickness is larger than minimum chip thickness,

$$
\begin{aligned}
& F_{x}(t)=R \cot \beta \int_{\theta_{e n}}^{\theta_{e x}}\left(K_{r c} h\left(\theta_{i}(z)\right) \sin \theta+K_{r e} \sin \theta+\ldots+K_{t c} h\left(\theta_{i}(z)\right) \cos \theta+K_{t e} \cos \theta\right) d \theta \\
& F_{y}(t)=R \cot \beta \int_{\theta_{e n}}^{\theta_{e x}}\left(K_{r c} h\left(\theta_{i}(z)\right) \cos \theta+K_{r e} \cos \theta-\ldots-K_{t c} h\left(\theta_{i}(z)\right) \sin \theta-K_{t e} \sin \theta\right) d \theta
\end{aligned}
$$

Where, $R$ is nominal radius of cutting tool; $\beta$ is the helix angle of cutting tools; $\theta_{\mathrm{en}}$ and $\theta_{\mathrm{ex}}$ are the entry angle and exit angle of cutting flute when it engages and disengages with workpiece material; $A_{p}$ is the ploughing area between the tool and workpiece; $\theta$ is the position angle. $\mathrm{K}_{\mathrm{rp}}, \mathrm{K}_{\mathrm{tp}}$ are the ploughing coefficients in radial and tangential directions respectively; $\mathrm{K}_{\mathrm{re}}, \mathrm{K}_{\mathrm{te}}$ are the edge constants in radial and tangential directions respectively; $\mathrm{K}_{\mathrm{rc}}, \mathrm{K}_{\mathrm{tc}}$ are the cutting force coefficients contributed by the shearing action in radial and tangential directions respectively.

Due to the periodical changes of cutting chip thickness, both ploughing dominant cutting 
and shearing dominant cutting will take place in each revolution. Thus, the cutting forces should be calculated comprehensively by combining equation (2) and equation (3). For ultra-precision micro milling, the cross section of the chip generated in micro milling is also a function of position angle. The cross section can be formulated in equation (4):

$$
S=\frac{R}{\sin \beta} \int_{\theta_{e n}}^{\theta_{e x}} h\left(\theta_{i}(z)\right) d \theta
$$
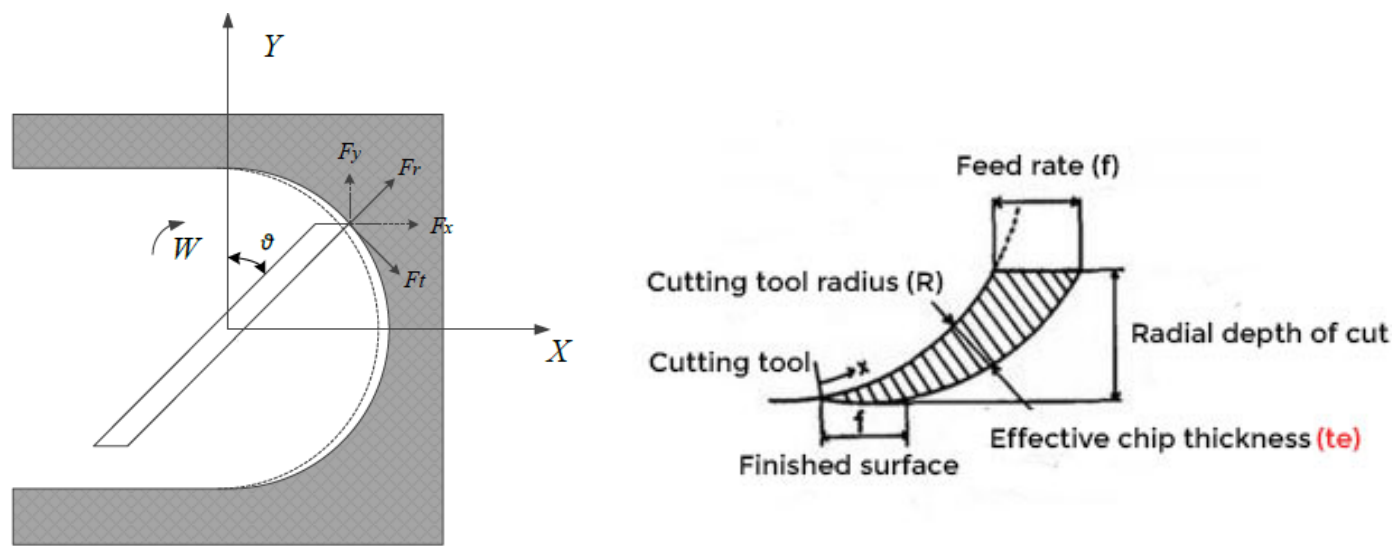

(a) The actual tool path and effective chip thickness in micro milling

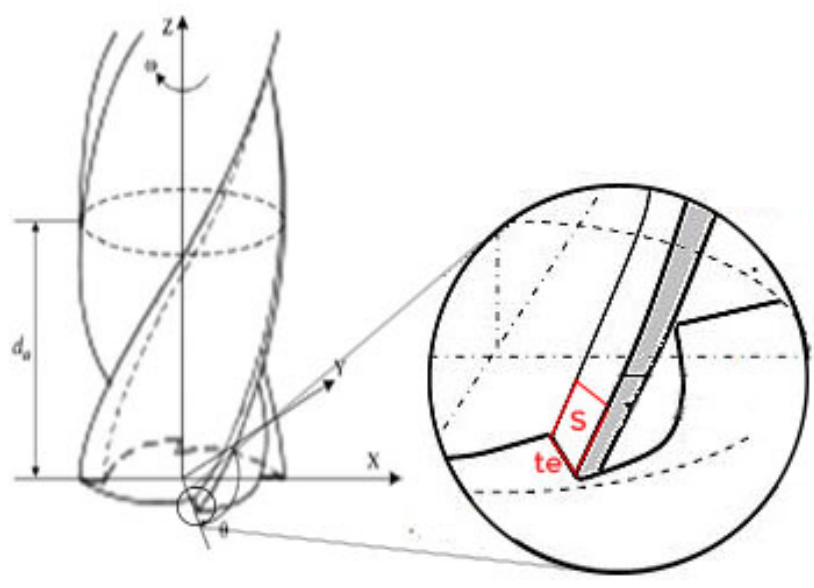

(b) Cross section of the chip generated in micro milling

Figure 1 Innovative modelling and analysis of the cutting force and chip formation

Where, $h(\theta i(z))$ is the uncut chip thickness which is a function of tool position angle $\theta$ and flute axial height $z ; \mathrm{t}$ is the time point of milling process; $\mathrm{k}$ is the tooth number of micro mill. Thus, the specific cutting force at unit area that overcomes the ultimate 
strength for the chip formation shown in Figure 1 can be formulated as equation (5):

$$
\begin{aligned}
& F_{S x}(t, k)=\frac{F_{x}(t) \sin \beta}{R \int_{\theta_{e n}}^{\theta_{e x}} h\left(\theta_{i}(z)\right) d \theta} \\
& F_{S y}(t, k)=\frac{F_{y}(t) \sin \beta}{R \int_{\theta_{e n}}^{\theta_{e x}} h\left(\theta_{i}(z)\right) d \theta}
\end{aligned}
$$

Thus, the cutting force at the unit area that presented as the specific cutting force clearly illustrates the insightful mechanics on the chip formation and breakage. This specific cutting force also bridge the intrinsic relationship between cutting force and chip formation in micro cutting aspects. In addition, the cutting mechanics particularly for the chip formation that analyzed by using the formulation of specific cutting force at unit area provide a scientific understanding on the chip formation mechanisms in micro milling process and also bridge the gaps for the intrinsic relationship of micro cutting mechanisms quantitatively at the high precision engineering level.

\section{Experimental set-up and micro milling trials}

\subsection{Experimental set-up}

The experiments are carried out by using a KERN HSPC precision micro milling machine which has a ceramic bearing supported spindle with maximum speed of 30,000 rpm, the motion accuracy of each linear axis is within $1 \mu \mathrm{m}$. To investigate the role of cutting edge radius and avoid the complexity brought about by multi-blades in oblique cutting, two single blade straight flute micro milling tools with the diameter of $0.4 \mathrm{~mm}$ are employed in micro milling experiments. The first tool is a single blade nature diamond milling tool with a very small cutting edge radius which is around $100 \mathrm{~nm}$ as shown in Figure 2(b); the second tool shown in Figure 2(c) is a single blade tungsten carbide tool which has a larger cutting edge radius. The cutting edge radius is normally $1 \sim 3 \mu \mathrm{m}$ due to the limitation of manufacturing process. The cutting edge radius of tungsten carbide tool and diamond tool used in the micro milling experiments are $1.4 \mu \mathrm{m}$ and $0.1 \mu \mathrm{m}$ respectively. The cutting 
edge radius of tungsten carbide tool and diamond tool as shown in Figure 2(d) are imaged by using JCM-6000 benchtop SEM and measured by using build-in tools in MATLAB. In micro milling process, cutting parameters are usually around micrometers. Given this fact, it is reasonable to assume that the natural diamond has sharp cutting edge. Thus, cutting process under conditions of sharp and round cutting edges can be investigated separately.

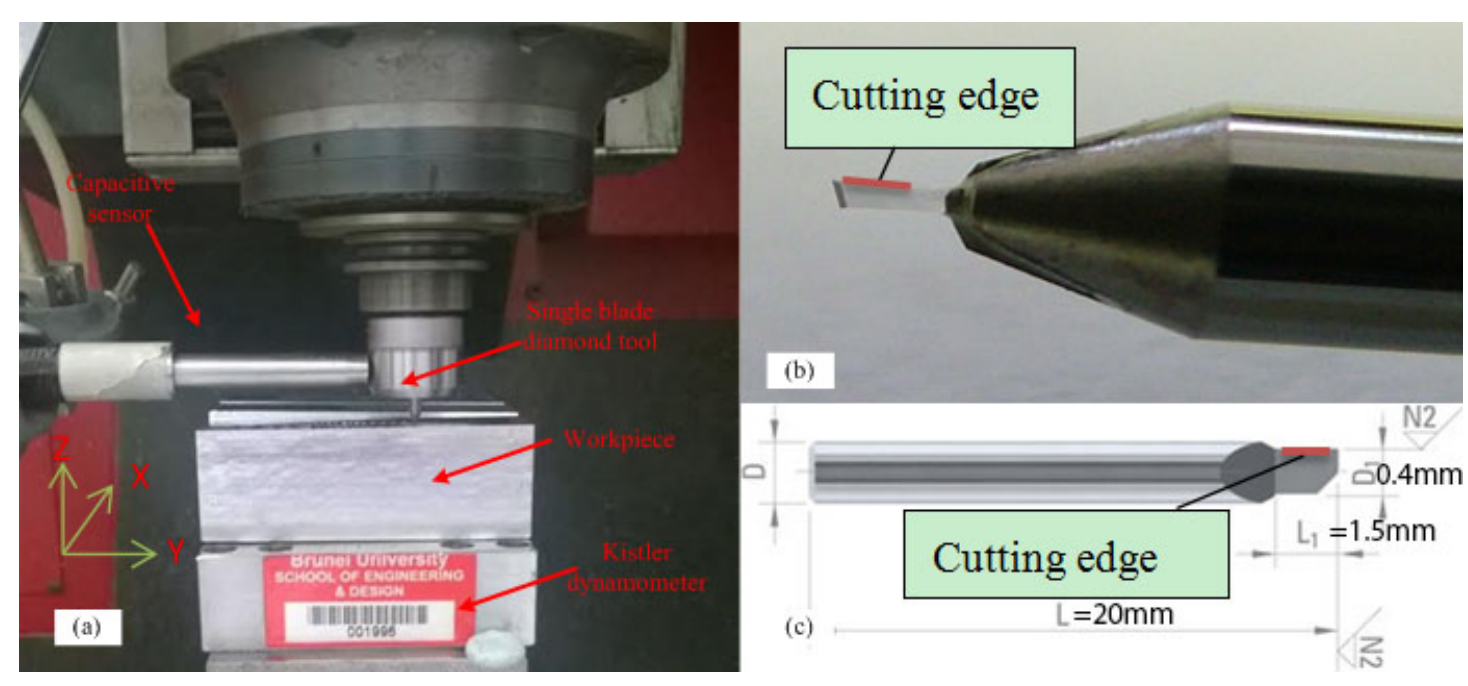

(a) Experimental set-up (b) Natural diamond single blade tool (c) Tungsten carbide single blade tool

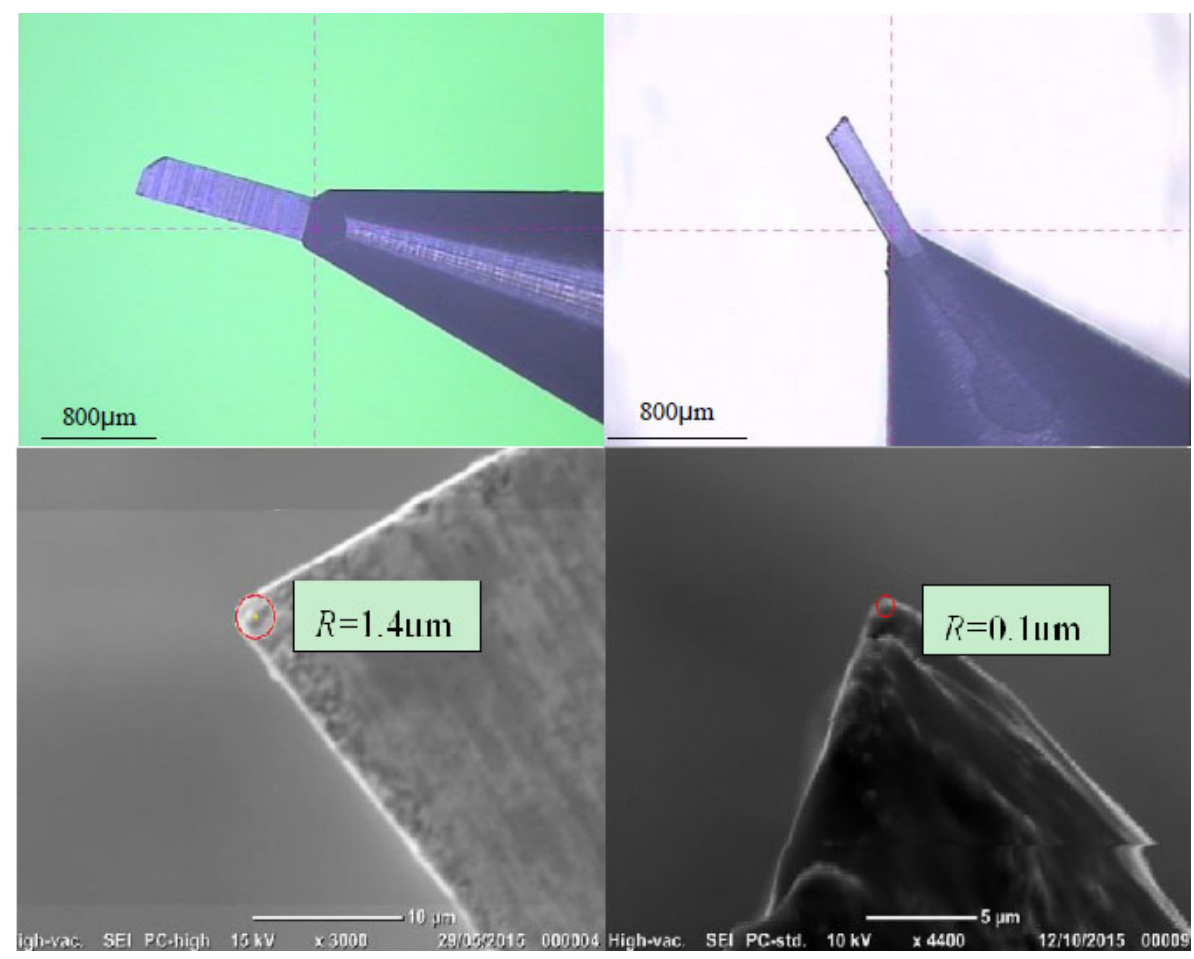

(d) The cutting edge radius of tungsten carbide tool (Left) and natural diamond tool (Right)

Figure 2 Experimental set-up and micro milling tools 
3.2 Experiment design and procedures

The experimental set-up for the full slot micro milling experiments on aluminum 6082-T6 workpiece with micro cutting tools is shown in Figure 2(a). The workpiece material specifications and properties are shown in Table 1.

Table 1 Workpiece material specifications and properties

\begin{tabular}{|c|c|}
\hline Physical parameter & Aluminum 6082-T6 \\
\hline Density, $\rho\left(\mathrm{kg} / \mathrm{m}^{3}\right)$ & 2700 \\
\hline Elastic modulus, $\mathrm{E}(\mathrm{GPa})$ & 71 \\
\hline Poisson's ratio, $\mathrm{v}$ & 0.33 \\
\hline Specific heat, $\mathrm{Cp}\left(\mathrm{J} / \mathrm{kg} /{ }^{\circ} \mathrm{C}\right)$ & 896 \\
\hline Thermal conductivity, $\lambda\left(\mathrm{W} / \mathrm{m} /{ }^{\circ} \mathrm{C}\right)$ & 170 \\
\hline Thermal expansion, $\alpha \mathrm{d}\left(\mu \mathrm{m} /{ }^{\circ} \mathrm{C}\right)$ & 24 \\
\hline $\mathrm{T}_{\text {melt }}\left({ }^{\circ} \mathrm{C}\right)$ & 583 \\
\hline $\mathrm{T}_{\text {room }}\left({ }^{\circ} \mathrm{C}\right)$ & 20 \\
\hline
\end{tabular}

In order to inspect the chips formed under varied cutting parameters, series of cutting trials are undertaken with both milling tools. The chips collected are observed by images under microscope and SEM. In terms of data acquisition system, a Kistler dynamometer 9256C2, which ranges from $-250 \mathrm{~N}$ to $250 \mathrm{~N}$ for each axis, connected to $\mathrm{PC}$ with $\mathrm{A} / \mathrm{D}$ is used as the cutting force data collection equipment. LabView 2013 software is used to record and analyze data of micro milling forces. To synchronize the cutting process and force recording, the capacitive sensor MicroSense 5810 is adopted. A mark is attached to the tool holder which is aligned with the single flute cutting edge. During machining, the mark is captured by the capacitive sensor which indicates the beginning of cutting process. Cutting forces are collected with a sampling rate of $51.2 \mathrm{KHz}$, which is high enough to accommodate most of the dynamic characteristic in micro cutting process. The workpiece, which is fixed on the dynamometer via the non-rigid connection, will change the dynamic response of the dynamometer. Thus, a hammer test is performed to obtain the altered transfer function from workpiece to dynamometer, and the collected cutting forces are compensated by applying an extended Kalman Filter ${ }^{[11]}$. The orthogonal array of cutting parameters in the full slot micro milling experiments is listed in Table 2. The cutting trials 
are conducted at varied spindle speed and feed rate. In addition, only one of them is varied while another is holding constant in order to observe the effects of input parameters. The axial depth of cut is kept in constant during the whole experiments. The cutting experiments are conducted under dry cutting condition, only air blow is adopted in the experiments.

Table 2 Orthogonal array of cutting parameters used in micro-milling

\begin{tabular}{|c|c|c|c|c|}
\hline $\begin{array}{c}\text { Experiment } \\
\text { No. }\end{array}$ & Tools & $\begin{array}{l}\text { Spindle speed } \\
(\mathrm{rpm})\end{array}$ & $\begin{array}{c}\text { Feed per tooth } \\
(\mu \mathrm{m} / \mathrm{rev})\end{array}$ & $\begin{array}{l}\text { Axial depth of } \\
\text { cut }(\mu \mathrm{m})\end{array}$ \\
\hline 1 & $\mathrm{~A} / \mathrm{B}$ & 12,000 & 0.2 & 20 \\
\hline 2 & $\mathrm{~A} / \mathrm{B}$ & 12,000 & 0.5 & 20 \\
\hline 3 & $\mathrm{~A} / \mathrm{B}$ & 12,000 & 1 & 20 \\
\hline 4 & $\mathrm{~A} / \mathrm{B}$ & 12,000 & 2 & 20 \\
\hline 5 & $\mathrm{~A} / \mathrm{B}$ & 12,000 & 3 & 20 \\
\hline 6 & $\mathrm{~A} / \mathrm{B}$ & 12,000 & 4 & 20 \\
\hline 7 & $\mathrm{~A} / \mathrm{B}$ & 12,000 & 5 & 20 \\
\hline 8 & $\mathrm{~A} / \mathrm{B}$ & 21,000 & 0.2 & 20 \\
\hline 9 & $\mathrm{~A} / \mathrm{B}$ & 21,000 & 0.5 & 20 \\
\hline 10 & $\mathrm{~A} / \mathrm{B}$ & 21,000 & 1 & 20 \\
\hline 11 & $\mathrm{~A} / \mathrm{B}$ & 21,000 & 2 & 20 \\
\hline 12 & $\mathrm{~A} / \mathrm{B}$ & 21,000 & 3 & 20 \\
\hline 13 & $\mathrm{~A} / \mathrm{B}$ & 21,000 & 4 & 20 \\
\hline 14 & $\mathrm{~A} / \mathrm{B}$ & 21,000 & 5 & 20 \\
\hline 15 & $\mathrm{~A} / \mathrm{B}$ & 30,000 & 0.2 & 20 \\
\hline 16 & $\mathrm{~A} / \mathrm{B}$ & 30,000 & 0.5 & 20 \\
\hline 17 & $\mathrm{~A} / \mathrm{B}$ & 30,000 & 1 & 20 \\
\hline 18 & $\mathrm{~A} / \mathrm{B}$ & 30,000 & 2 & 20 \\
\hline 19 & $\mathrm{~A} / \mathrm{B}$ & 30,000 & 3 & 20 \\
\hline 20 & $\mathrm{~A} / \mathrm{B}$ & 30,000 & 4 & 20 \\
\hline 21 & $\mathrm{~A} / \mathrm{B}$ & 30,000 & 5 & 20 \\
\hline
\end{tabular}

\section{Experimental results, analysis and discussion}

(1) Chip morphology in micro milling

Chips in all experiments are collected and then observed by images on the SEM machine and fully measured with build-in tools in MATLAB according to the imaged scale on the 
SEM. Figure 3 and Figure 4 show the selected measured produced chips at varied feed rate by using diamond tools and tungsten carbide tools respectively. The formed chips are measured randomly and replicable for each cutting parameters and these measured chips do not show significantly variation. Therefore, the chip characteristics illustrated in these figures can represent almost all chips in micro milling processes.

Due to the cutting edge radius is quite small, the diamond tool can be treated as perfectly sharp. Thus, the minimum chip thickness, which is approximately half the tool edge radius, is not accounted ${ }^{[12]}$. The produced diamond cutting chips are partly shown in Figure 3, the front-end points and trailing edge as marked in Figure 3(b) can be both clearly identified in one chip segment, which means the chips are formed continuously in each revolution. The front and end point are located at the two sides of the formed chips. According to the chip formation scenario, the inner side end of these curled chips is observed as the front point where chips formation begins at this point; while the outer side end of these curled chips is observed as the end point where chips formation is ended. The upper surface of chips exhibits ribbon-like topography which is the direct result of material shearing during chip formation; the diamond tool has very good surface finish on rake face and the frictional coefficient at the interface is low as well. These properties make the chips less attachable to the tool, thus, the lower surface of the chip is very smooth ${ }^{[13]}$. As the feed rate increases, the chip thickness and the stress at the interface increase as well. The lower surface becomes slightly rougher as shown in Figure 3(c).

The average overall length of chips measured at varied feed rate is around $250 \mu \mathrm{m}$ and these lengths of chips do not show much variation. While the theoretical chip length in the full slot milling is around $630 \mu \mathrm{m}$, it can be illustrated that the deformations make the chip short, consequently chip thickness increases. The maximum thickness along the chip is measured around $1 \mu \mathrm{m}, 5 \mu \mathrm{m}$ and $9 \mu \mathrm{m}$ for the feed rate of $0.5 \mu \mathrm{m} /$ tooth, $2 \mu \mathrm{m} /$ tooth and 4 $\mu \mathrm{m} /$ tooth respectively. Thus the chip thickness ratio can be estimated to be around 0.5 for diamond tool. Chips under varied cutting speed are also examined in these experiments. The results show no distinct variation in aspects of chip thickness, length and continuity. It can be concluded that cutting speed has quite small influence on chip formation; this is in 
alignment with the workpiece material properties which have low strain rate sensitivity ${ }^{[14]}$.

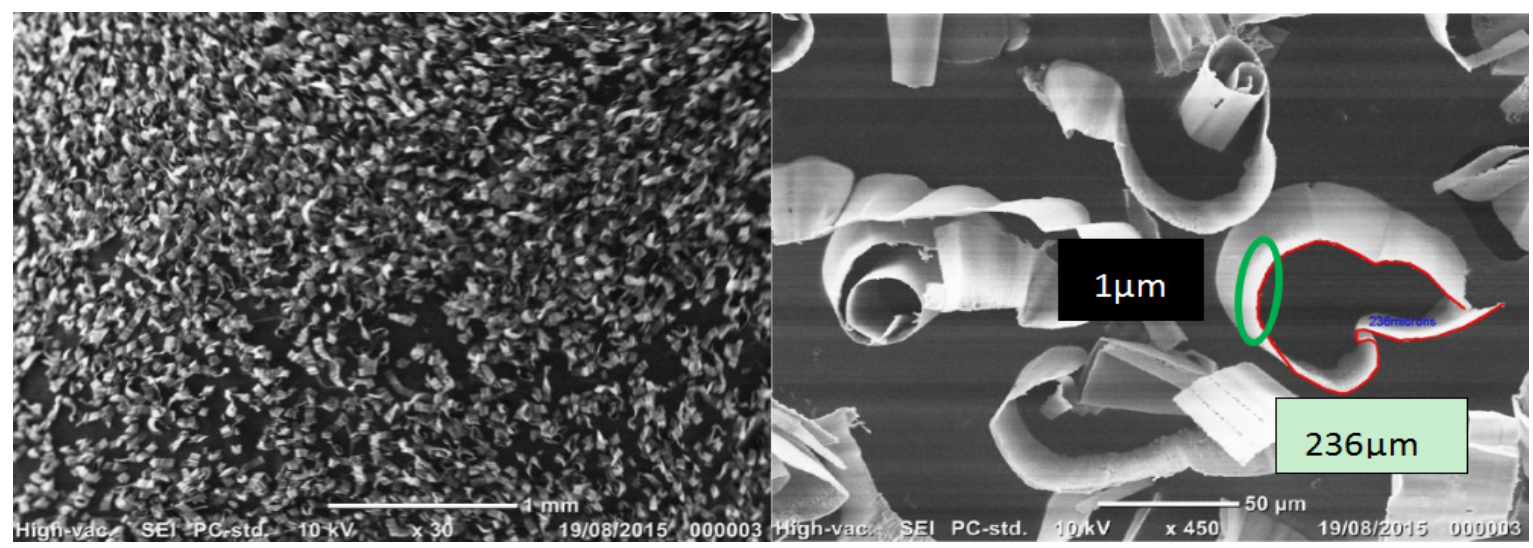

(a) Chips formed at feed rate $0.5 \mu \mathrm{m} /$ tooth. Left: zoom x30. Right: zoom x450.

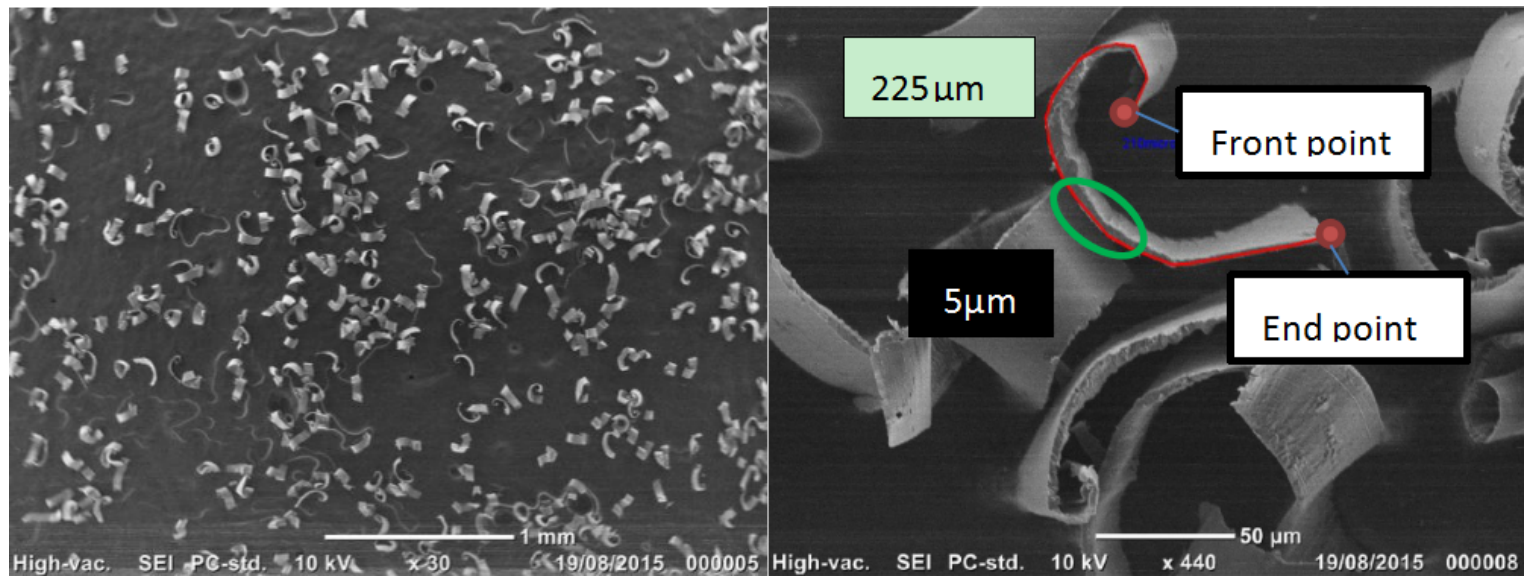

(b) Chips formed at feed rate $2 \mu \mathrm{m} /$ tooth. Left: zoom x30. Right: zoom x440.

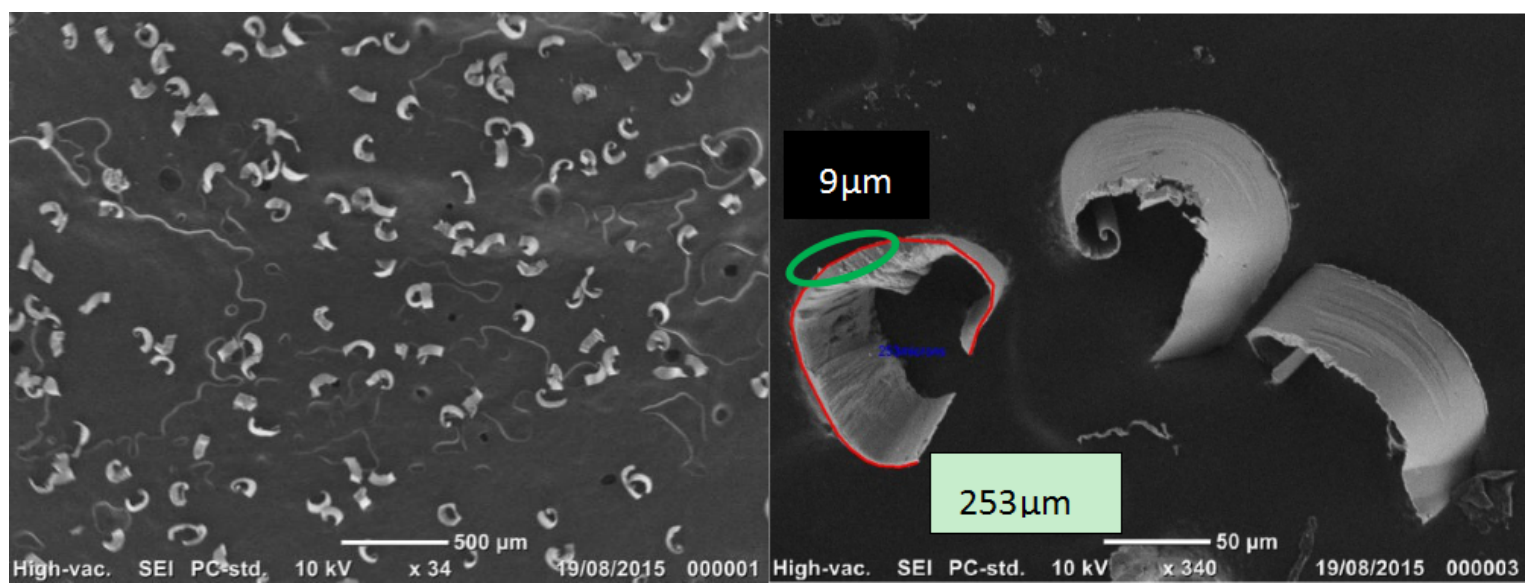

(c) Chips formed at feed rate $4 \mu \mathrm{m} /$ tooth. Left: zoom x34. Right: zoom x340.

Figure 3 Chips formed by diamond tools (spindle speed: 21,000 rpm) 
For tungsten carbide tool, it can be observed that the cutting edge radius around $1.4 \mu \mathrm{m}$ as shown in Figure 2(d) cannot be ignored compared to the adopted cutting parameters. Normally, the minimum chip thickness is around $20 \%-30 \%$ of cutting edge radius and can be down to $5 \%$ of edge radius when cutting aluminum ${ }^{[15-17]}$. Thus, the chip formation for micro cutting with tungsten carbide tool can be concluded as follows. If the feed per tooth is smaller than the minimum chip thickness, chips will not be generated in each revolution. If the feed per tooth is much larger and exceed the minimum chip thickness, chips will be formed in each revolution. Based on the ratio found in previous session ${ }^{[11]}$, the calculated minimum chip thickness will be around $15 \%$ of the edge radius of tungsten carbide tool for the micro cutting on aluminum6082-T6. Thus, the minimum chip thickness is around $0.21 \mu \mathrm{m}$ in this case.

The feed rate is varied among $0.2 \mu \mathrm{m} / \mathrm{z}, 0.5 \mu \mathrm{m} / \mathrm{z}, 2 \mu \mathrm{m} / \mathrm{z}$ and $4 \mu \mathrm{m} / \mathrm{z}$ in the experiments. Chips formed in micro milling experiments are partly shown in Figure 4Figure, it can be seen that as the feed rate increases, the theoretical chip thickness becomes larger and chip length becomes longer. Thus, the larger real chip thickness formed the longer chips length formed. While the experimental chip length decrease with the increase of feed rate. This can be illustrated that with the feed rate increase, the increased chip thickness leads to the chip likely to break into pieces instead of forming continuous chips. The chip length is indicated in Figure 4 and it can be seen that chip length at $0.2 \mu \mathrm{m} /$ tooth feed rate is even longer than that at $0.5 \mu \mathrm{m} /$ tooth. However, considering the theoretical chip length is around $630 \mu \mathrm{m}$, the real chip length is obviously much bigger. It should also be noted that chip thickness is very even along the chip as shown in these figures. The measured thickness is around $3 \mu \mathrm{m}, 4 \mu \mathrm{m}, 11 \mu \mathrm{m}$ and $18 \mu \mathrm{m}$ respectively. The chip thickness ratios in these experiments are $1 / 15,1 / 8,1 / 5.5$ and $1 / 4.5$ respectively, which are quite smaller than that in chips formed by diamond tools. These two experiments indicate that the volume of each chip formed in micro milling process is much larger than the theoretical volume of chip that can be removed in single revolution. Based on the measured chip length and chip thickness, we can conclude that the long chips are consisted of many chips from consecutive revolutions. Due to the large cutting edge radius and strong interaction 
between the tool and workpiece material, the chip formed in preceding revolution may remain attached to the tool, and the chip keep forming in current revolution. As a result, the two chips will be joined together at the round tool tip under huge compressive and shearing stress. The larger the feed rate is, the more likely this phenomenon will happen. The material adhesive attachment on tungsten carbide tool during the micro milling process is shown in Figure 5. Thus, the reason for the longer chips formed at feed rate of $0.2 \mu \mathrm{m} /$ tooth than that at $0.5 \mu \mathrm{m} /$ tooth is related to the cutting edge radius. Chips may not form during one revolution until the accumulated chip thickness is large enough.

Another point to notice for micro milling with tungsten carbide tool is that the ribbon-like topography of upper surface is much more obvious, apart from the bigger friction at the interface, the large cutting edge radius, which subjects material to even severe ploughing and deformation, can be another contributing factor. As in this case, the chips are assumed to be formed by using a tool with large negative rake angle. The lower surface is comparatively smooth, as the chips move along tool rake face.

Experiments are also carried out at varied cutting speeds shown in Figure 6. The results show no significant change in terms of average chip thickness and continuity, which are the similar results of chips produced by diamond tool.

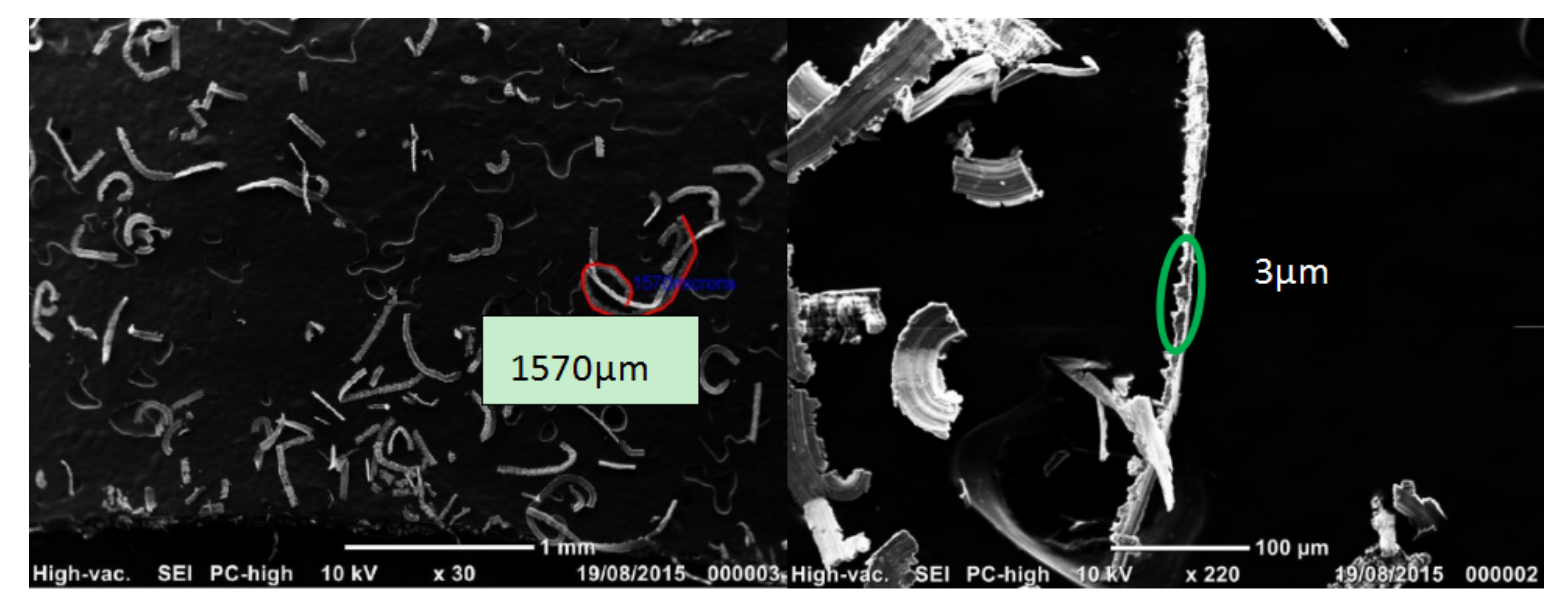

(a) Chips formed at feed rate $0.2 \mu \mathrm{m} /$ tooth. Left: zoom x 30. Right: zoom x 220 . 


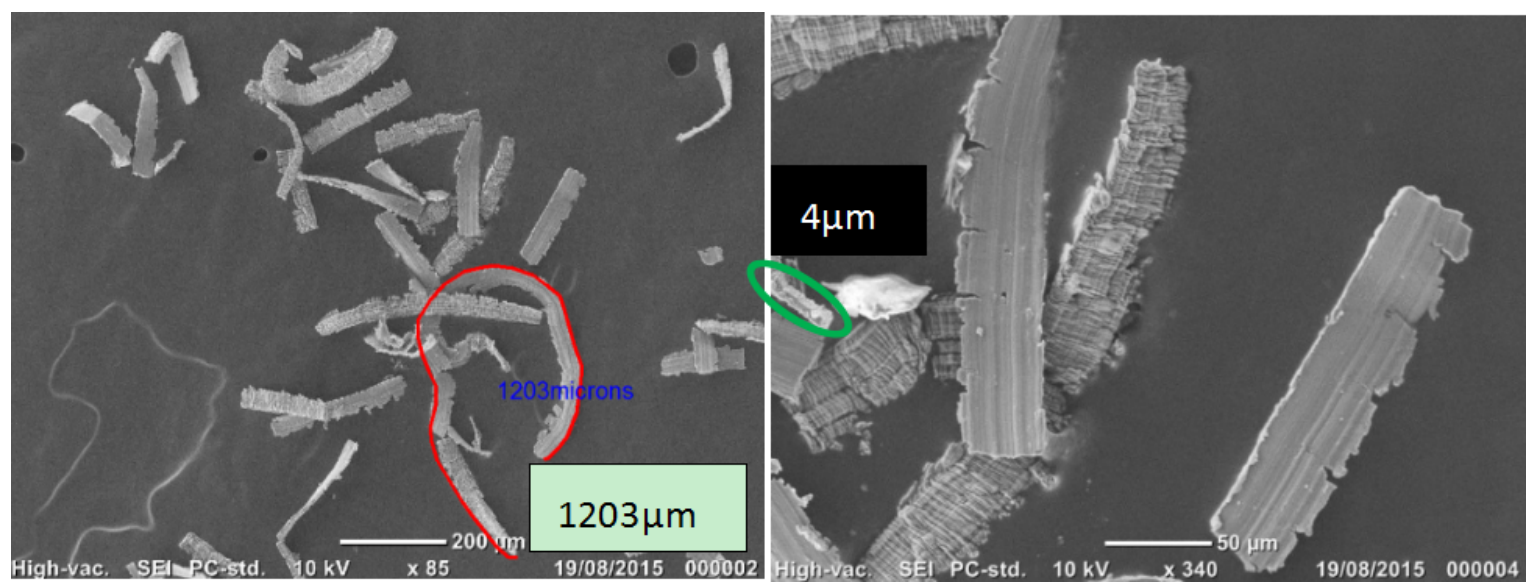

(b) Chips formed at feed rate $0.5 \mu \mathrm{m} /$ tooth. Left: zoom x 27. Right: zoom x 340 .

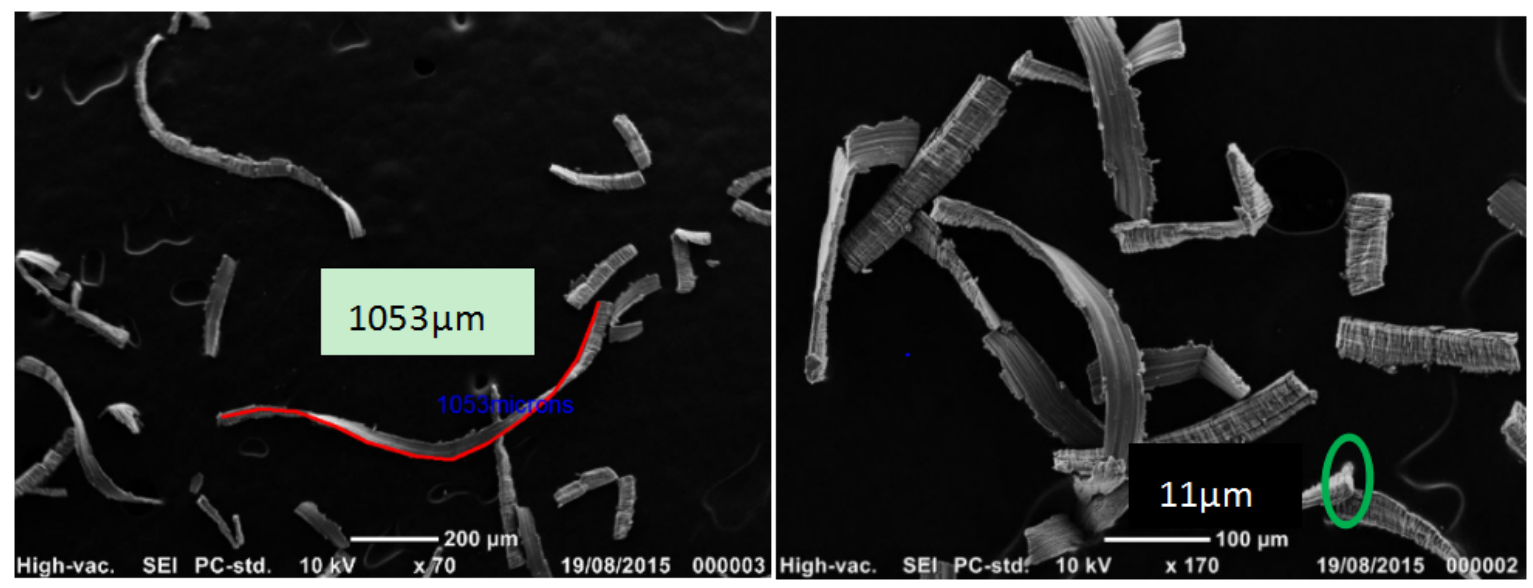

(c) Chips formed at feed rate $2 \mu \mathrm{m} /$ tooth. Left: zoom x 45. Right: zoom x 170 .

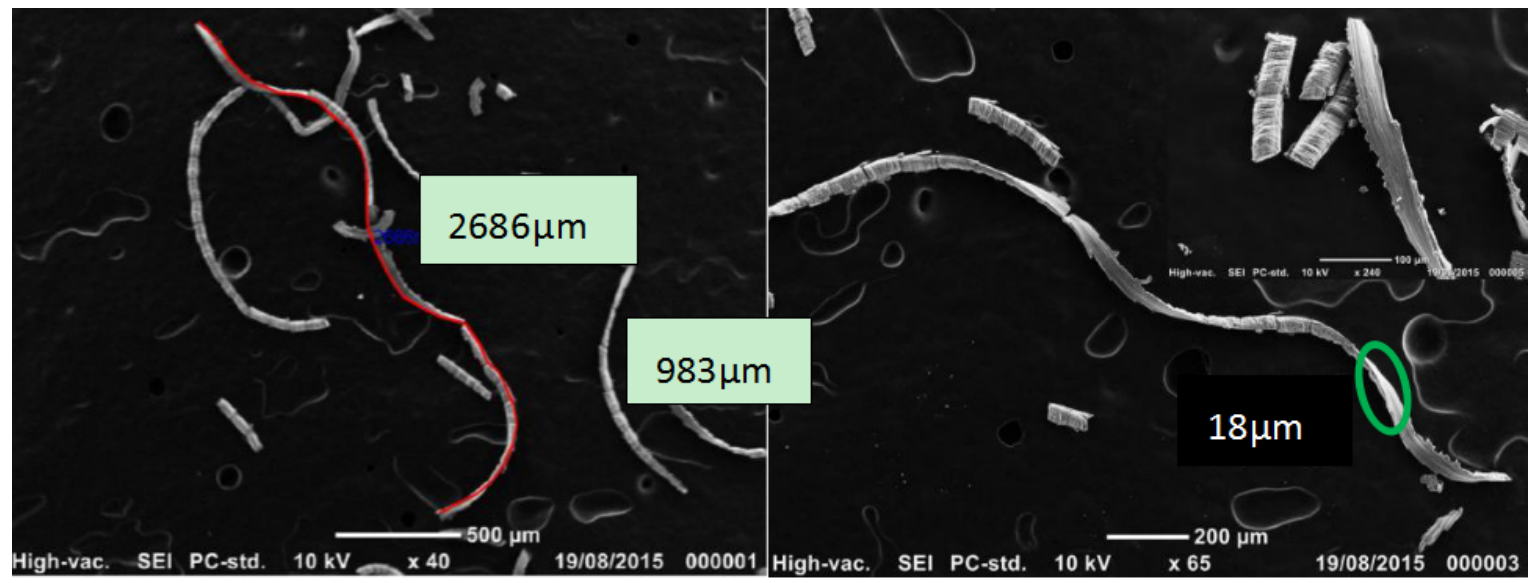

(d) Chips formed at feed rate $4 \mu \mathrm{m} /$ tooth. Left: zoom x 40. Right: zoom x 65 .

Figure 4 Chips formed by using tungsten carbide tools (spindle speed: 21,000 rpm) 


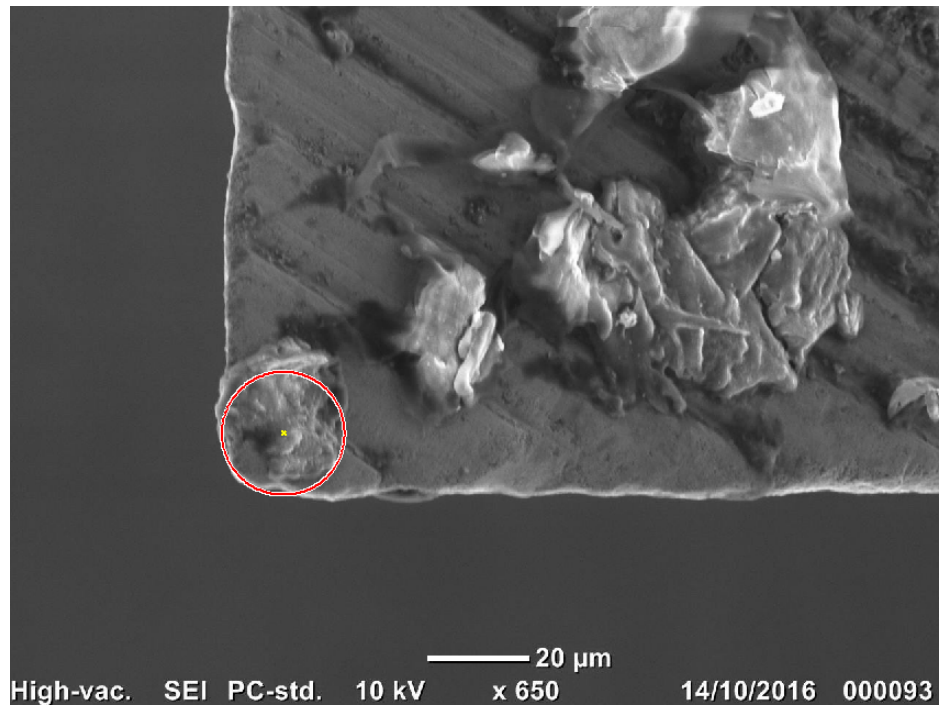

Figure 5 Material attachments on the tungsten carbide tool

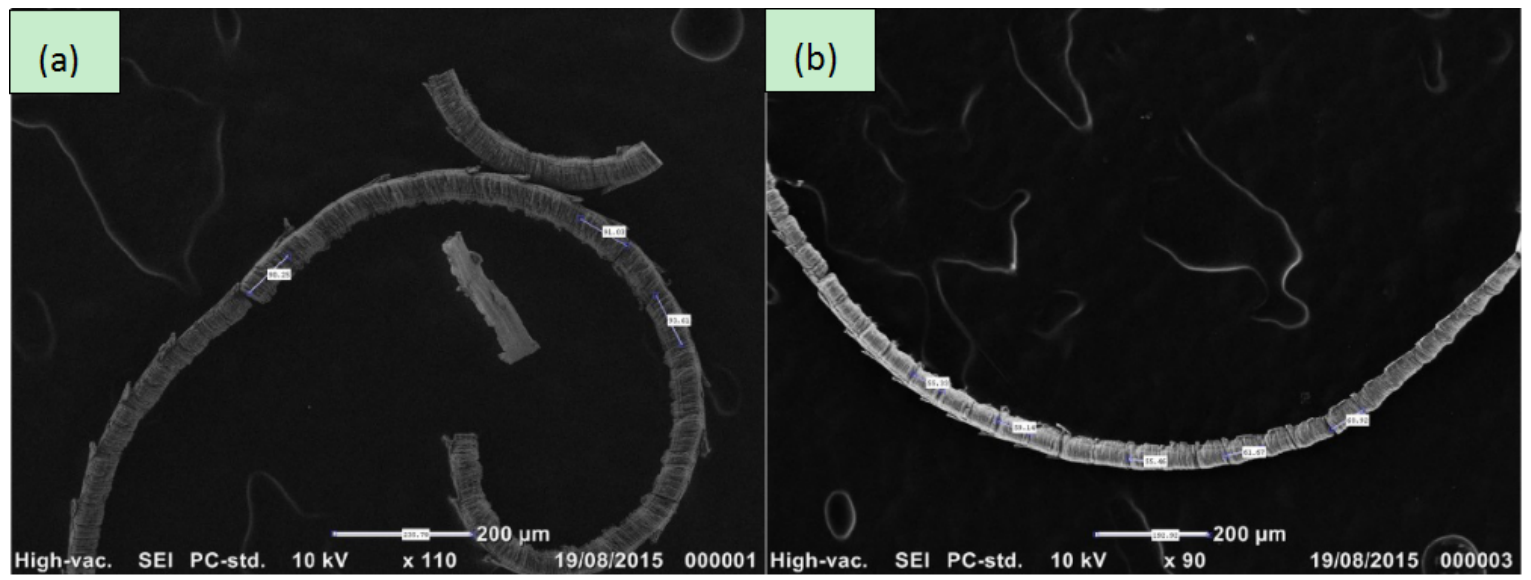

Figure 6 Chips formed at varied cutting speed (a) 12,000 rpm (b) 30,000 rpm

By comparing the experimental results of chip formation by using diamond tools and tungsten carbide tools, it can be significantly observed that the existence of cutting edge radius may change the chip formation process by concatenating chips among consecutive revolutions, which results in longer chips. In addition, the chip thickness will be more even compared to that formed by sharp edge diamond tool. Moreover, material is subject to even severe shearing and deformation under the condition of large cutting edge radius.

(2) Cutting forces in micro milling

Cutting forces data are collected to help interpret the cutting process and its dynamics, especially for the influence of cutting edge radius on force variation. Figure 7 shows the 
cutting forces in three directions at feed rate of $4 \mu \mathrm{m} /$ tooth and spindle speed of $21,000 \mathrm{rpm}$ by using a tungsten carbide tool. It typically shows how the cutting forces evolve in micro-milling process. The chip formation is a cyclic and periodic process in which tool enters and exits workpiece material periodically. Thus, the cutting forces data recorded are also periodic. The black vertical line indicates the beginning position which means tool starts cutting on the workpiece at this point. It can be seen that cutting forces increase in all of 3 direction with the machining continues, while, the force reaches the positive maximum at about $30^{\circ}$ rotational angle in $\mathrm{x}$ direction and then decreases. In addition, the chip thickness becomes larger gradually with the tool rotates. The cutting force then reaches the negative maximum at about $136^{\circ}$ rotational angle. Afterwards, it increases again and the chip thickness decreases until the tool tip approaches the exit point of cutting process. The force in y direction reaches positive maximum at the rotational angle around $70^{\circ}$ and then decreases, it reaches the negative maximum point at about $180^{\circ}$. The cutting force in $\mathrm{z}$ direction also increases firstly followed by the increases of chip thickness. At about $130^{\circ}$, it reaches the maximum, and then reduces to the minimum. In ideal situations, the tool exits and disengages the workpiece at rotational angle of $180^{\circ}$, the cutting force in each direction should become zero. However, the cutting forces in each latter half revolution are not zero as shown in Figure 7. It can be conclude that the noise is still present after force compensation and also, considering the movement of the machine, these are the effects of noise introduced by feed in micro milling process.

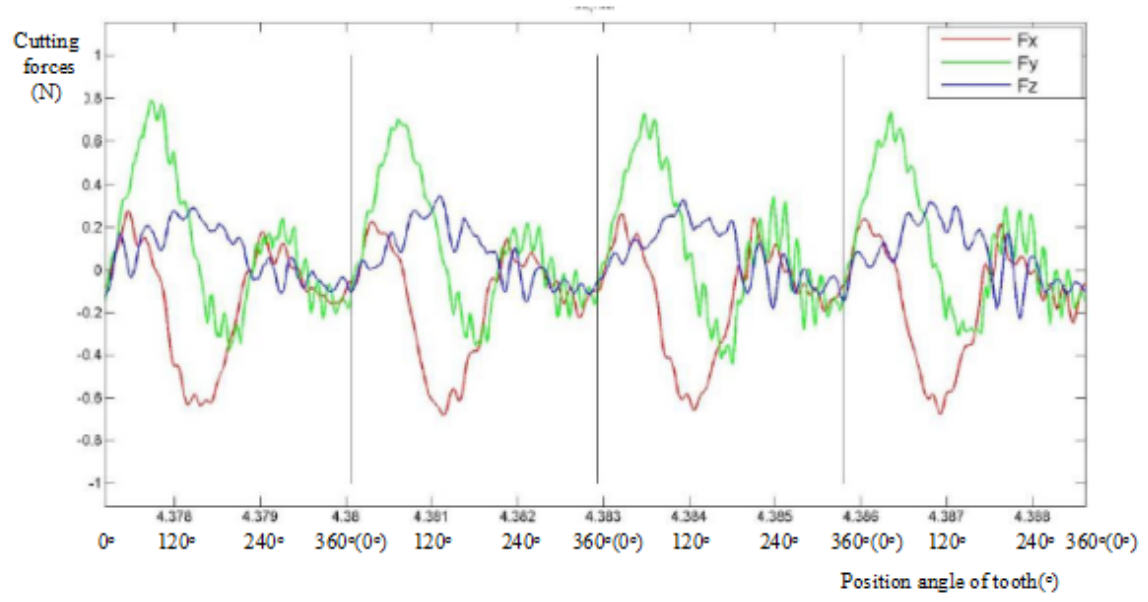

Figure 7 Cutting forces in machining aluminum by using tungsten carbide tools (feed rate: $4 \mu \mathrm{m} / \mathrm{r}$ ) 
Experiments are carried out with both diamond tools and tungsten carbide tools at varied feed rate and cutting speed. The following images in Figure 8 show the cutting force (Red: Fx; Green: Fy; Blue: Fz) during the machining processes by using these tools. Feed rates are varied among $0.5,1,2,3,4 \mu \mathrm{m} /$ tooth, which are above the minimum chip thickness of $0.2 \mu \mathrm{m}$ to assure the chip formation. It can be seen that cutting forces in both columns increase as the feed rate increases. However, for micro milling by using diamond tools, the resultant cutting forces at the same cutting parameters are much smaller than that using tungsten carbide tools.
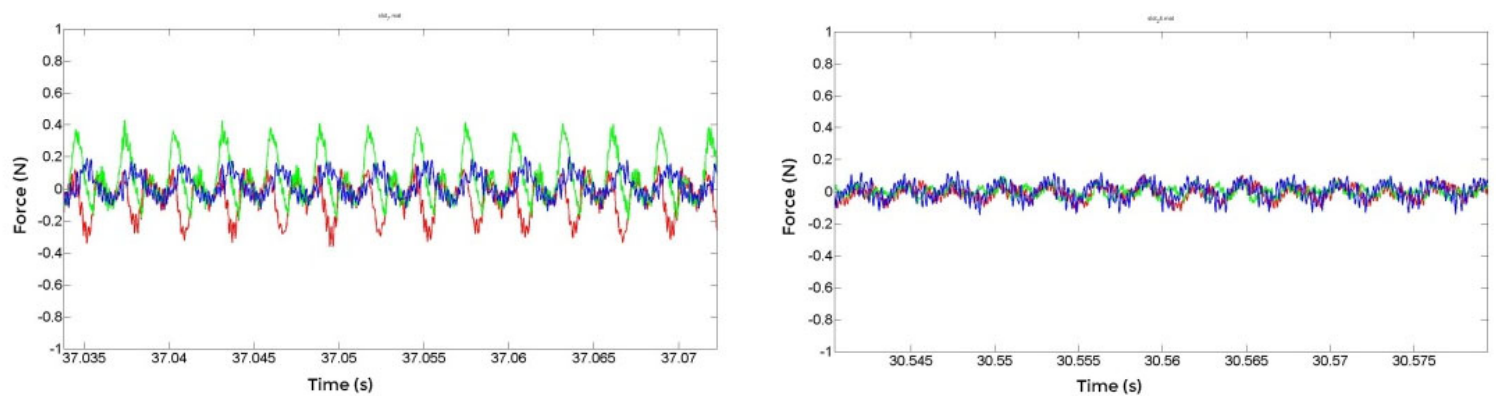

(a) Cutting forces at $0.5 \mu \mathrm{m} /$ tooth - Left: tungsten carbide tool; Right: diamond tool
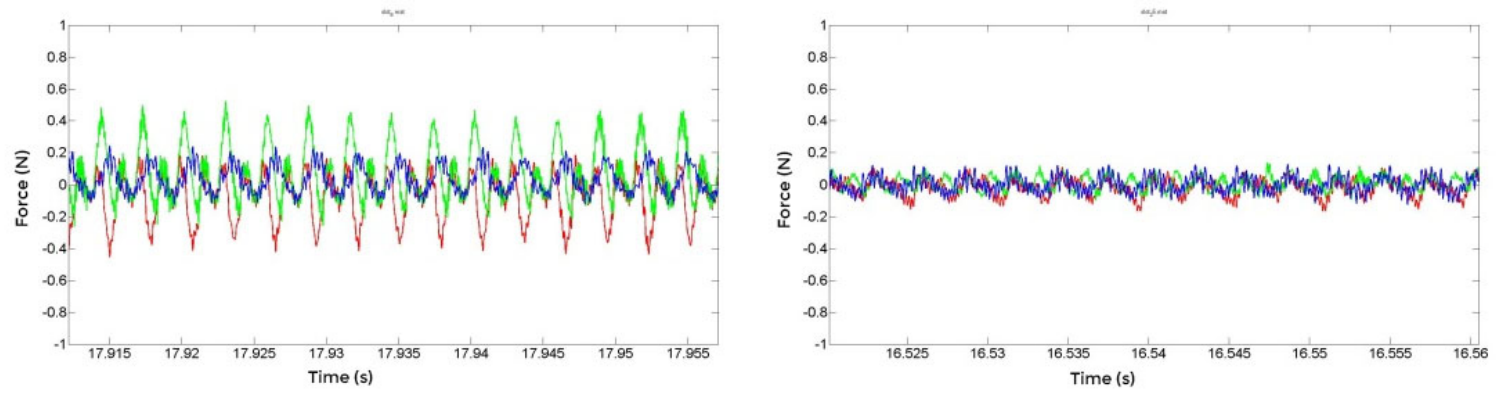

(b) Cutting forces at $1 \mu \mathrm{m} /$ tooth - Left: tungsten carbide tool; Right: diamond tool
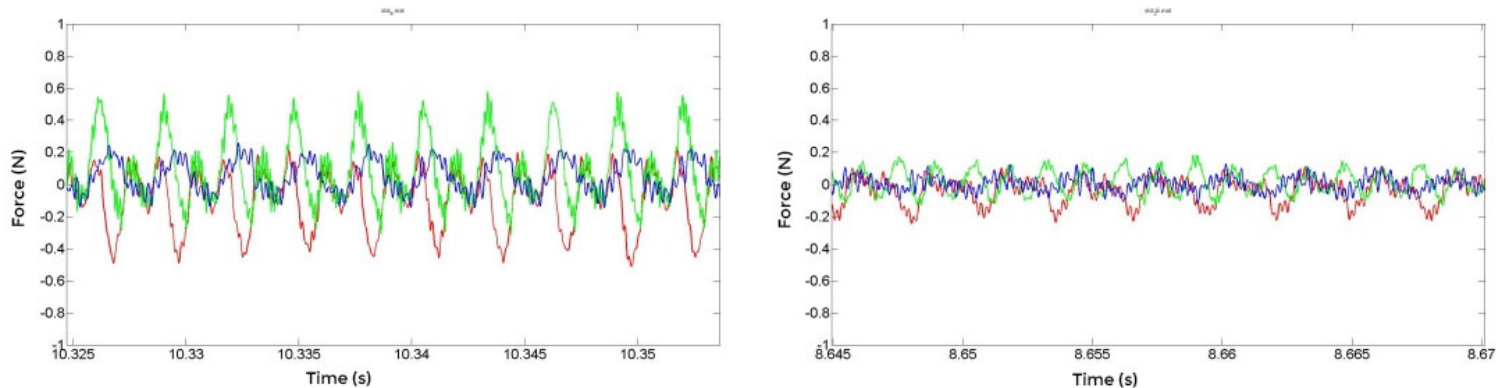

(c) Cutting forces at $2 \mu \mathrm{m} /$ tooth - Left: tungsten carbide tool; Right: diamond tool 

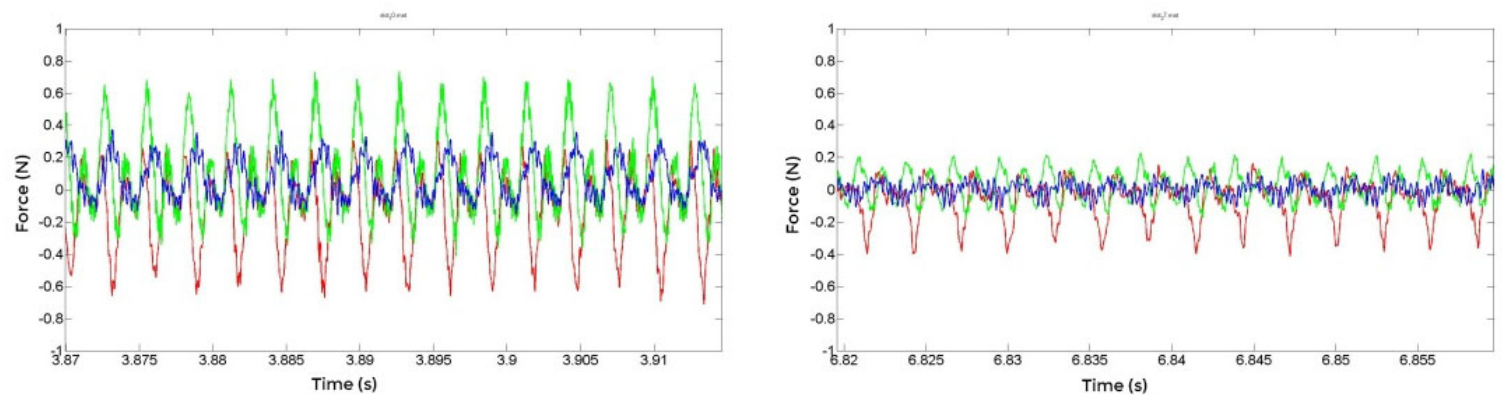

(d) Cutting forces at $3 \mu \mathrm{m} /$ tooth - Left: tungsten carbide tool; Right: diamond tool
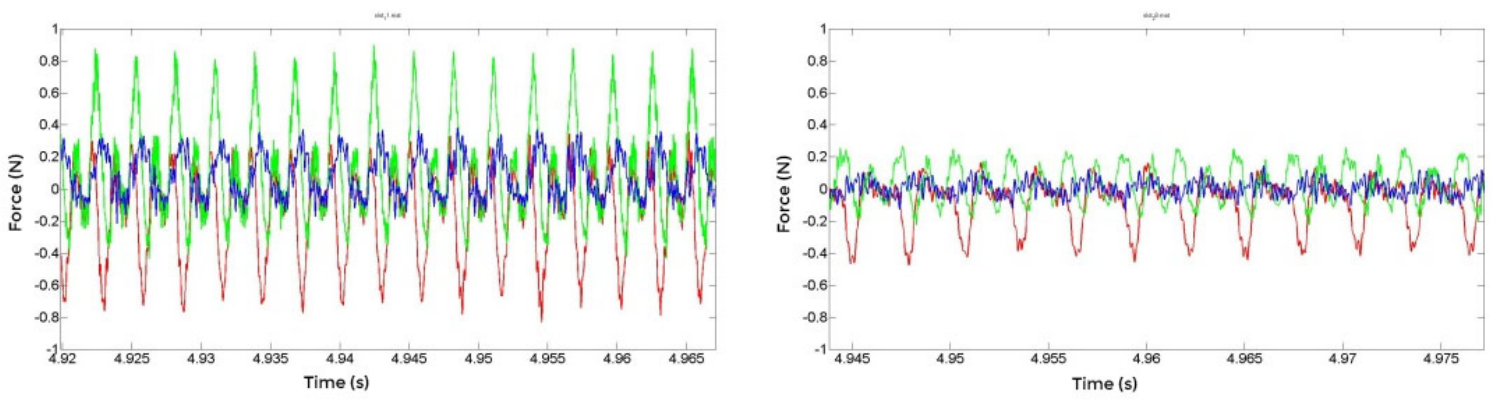

(e) Cutting forces at $4 \mu \mathrm{m} /$ tooth - Left: tungsten carbide tool; Right: diamond tool

Figure 8 Cutting force at varied feed rates by using two different tools at the spindle speed of 21,000 rpm

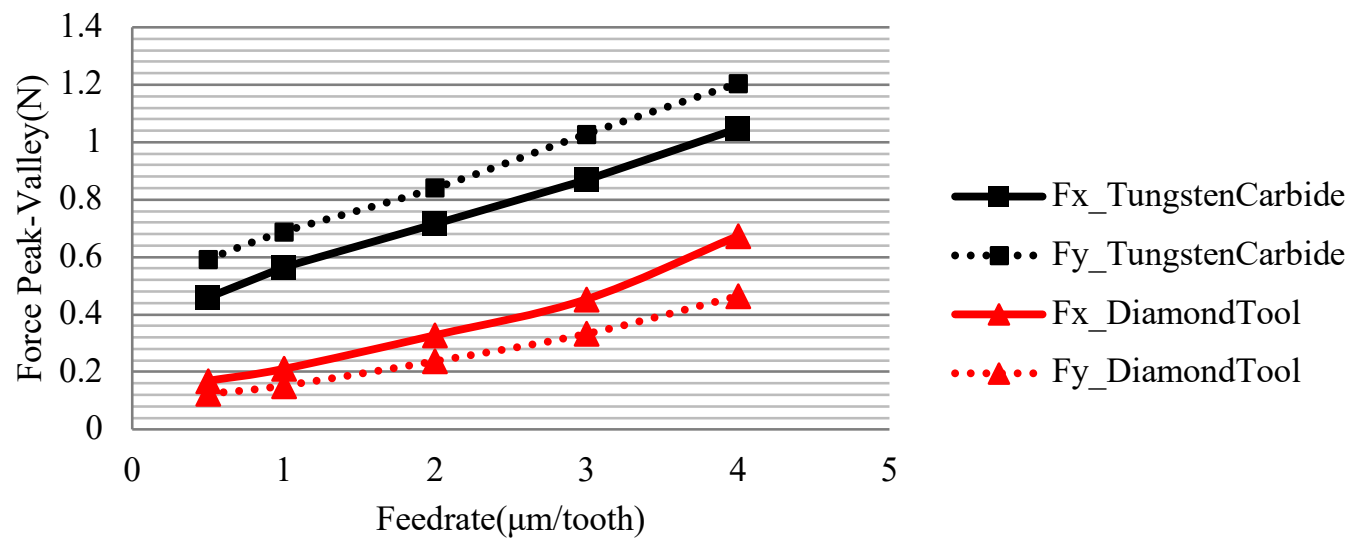

Figure 9 Peak-to-Valley force in $\mathrm{x}$ and $\mathrm{y}$ direction

The resultant Peak-to-Valley forces in $\mathrm{x}$ and $\mathrm{y}$ directions are plotted against the feed rate for the two tools in one revolution as illustrated in Figure 9. The peak-to-valley force when micro milling with a tungsten carbide tool is usually 2-3 times higher than that with a natural diamond tool. This can be resulted from rough frictional properties and large 
cutting edge radius of the tungsten carbide tools. To further analyse this, the cutting forces and thrust forces within each revolution are computed for both tool types, i.e. the tungsten carbide tool and the natural diamond tool.

The following images show the cutting and thrust forces in machining processes by using tungsten carbide and diamond tools respectively. It can be clearly seen that both the cutting force and thrust force are much larger for tungsten carbide tools than that for diamond tools. However, the force variations are quite different for two tools. For tungsten carbide tools, as commonly known, when chips are formed, the cutting forces should be larger than thrust forces due to dominant shearing and cutting process. However, on the contrary, the left column of Figure 10 shows that the magnitude of thrust force (in red) is larger than that of cutting force (in green). Take Figure 10(e1) as example, it shows that both cutting force and thrust force increase at the beginning. With the micro machining continuous (vertical line), the thrust force quickly rises up and exceeds the cutting force, then continues to the maximum, afterward it descends again below the cutting force and to the minimum as the tool exits material. The cutting force rises up simultaneously firstly with the thrust force and then drops back to a local minimum. At about the same position where the thrust force descends, the cutting force increases again to the maximum, then it descends again to the minimum. Taking amount of the chip formation process, the strong attachment between tool and workpiece material makes the produced chip adhere to the tool, which enlarges the actual cutting edge radius. The ploughing effect at the beginning of machining is more severe, so both cutting forces and thrust forces increase quickly. As the uncut chip thickness accumulates, the material starts to shear which results in the decline of cutting force, however, thrust force continues to rise until the cutting chips formed. Once chips are formed and joined together with the chips formed in previous revolution, the thrust forces decline quickly and cutting forces rise to the maximum and then decline due to the descending chip thickness. 

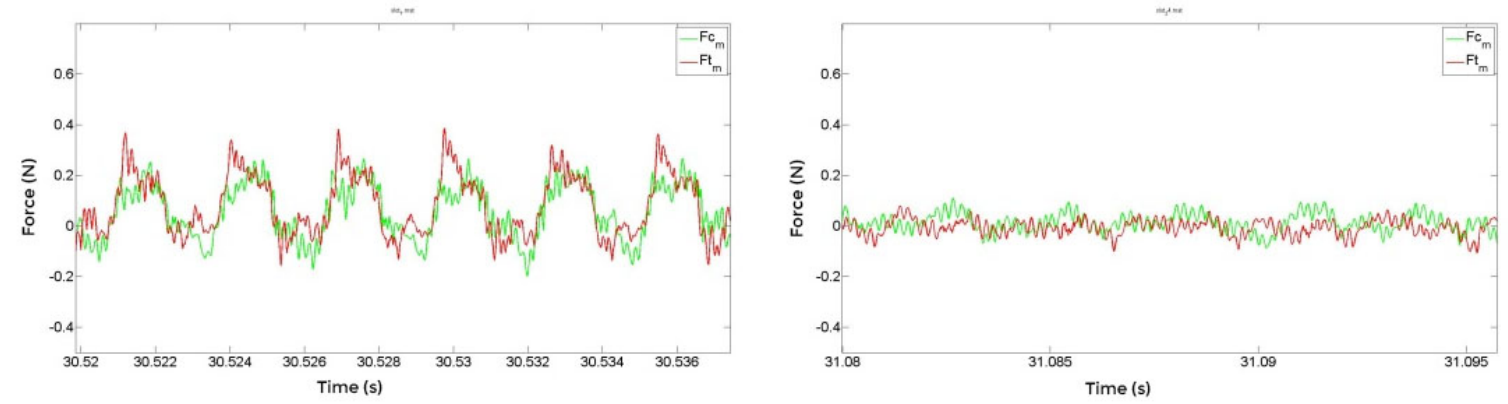

(a) Cutting forces at $0.5 \mu \mathrm{m} /$ tooth - Left: tungsten carbide tool; Right: diamond tool
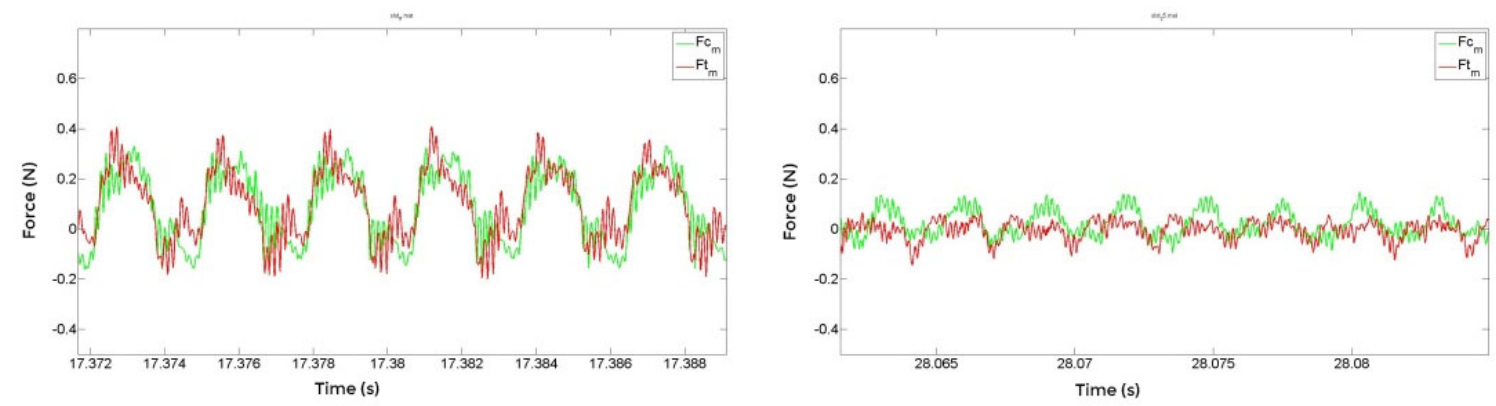

(b) Cutting forces at $1 \mu \mathrm{m} /$ tooth - Left: tungsten carbide tool; Right: diamond tool
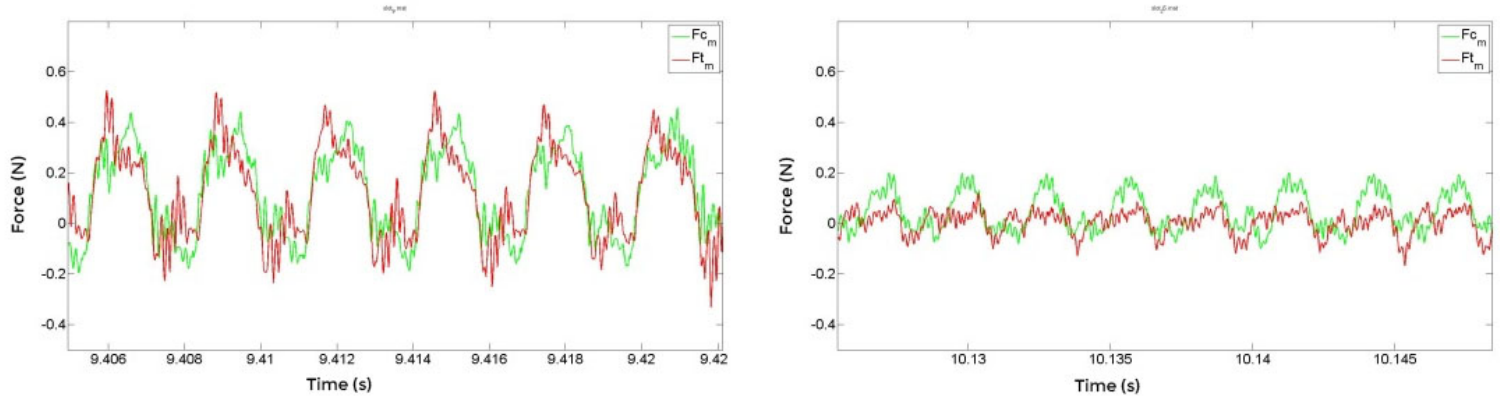

(c) Cutting forces at $2 \mu \mathrm{m} /$ tooth - Left: tungsten carbide tool; Right: diamond tool
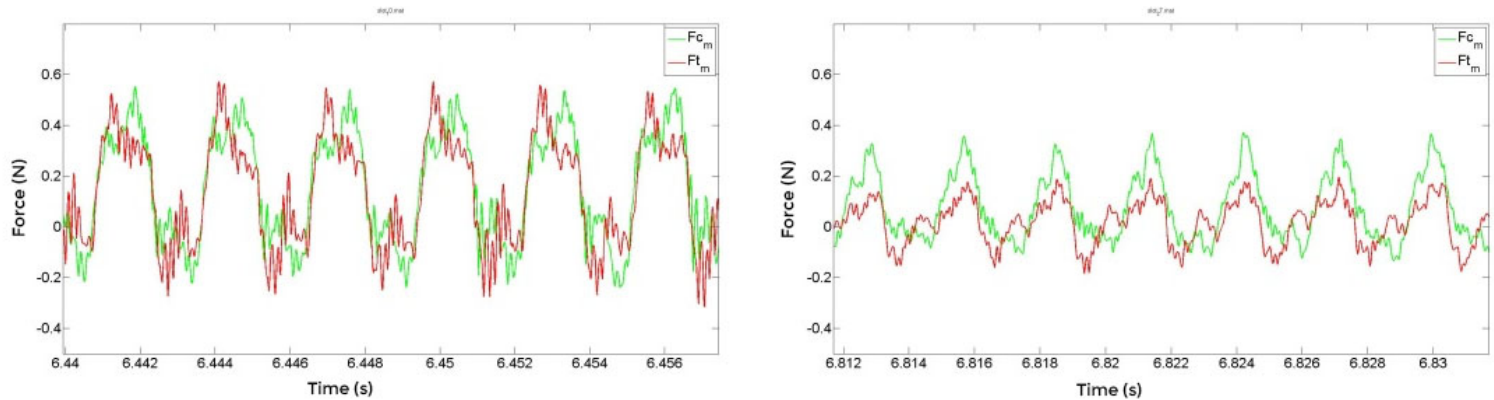

(d) Cutting forces at $3 \mu \mathrm{m} /$ tooth - Left: tungsten carbide tool; Right: diamond tool 

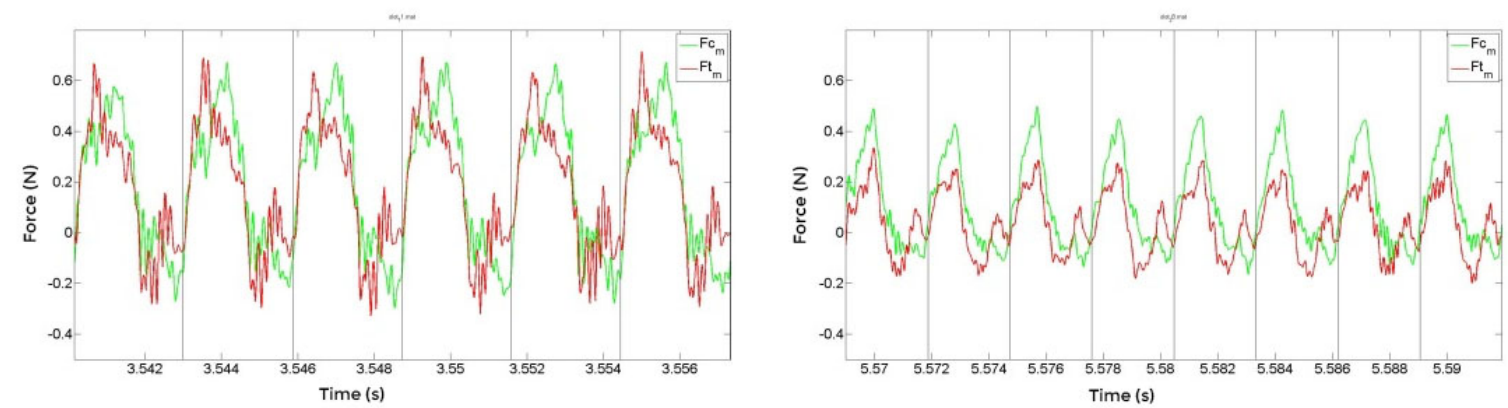

(e) Cutting forces at $4 \mu \mathrm{m} /$ tooth - Left: tungsten carbide tool; Right: diamond tool

Figure 10 Cutting force and thrust force by using tungsten carbide tools and diamond tools in micro milling processes (Red: thrust force; Green: cutting force)

For diamond tool, the cutting forces and thrust forces are much smaller, as feed rate increases, the magnitude gradually increases. The differences between cutting force and thrust force become more obvious. It can be observed from Figure 3, intact chips are formed consecutively in each revolution and the diamond tool is assumed to have sharp cutting edge compared to the cutting parameters. Related effect such as size effect and minimum chip thickness cannot be observed in cutting forces. The forces in Figure 10(e2) reveal that cutting forces are always larger than thrust forces during chip formation processes. Unlike tungsten carbide tool, the cutting forces and thrust forces reach the maximum at the same position in diamond machining, which is around $110^{\circ}$ from the beginning point. In addition, it also can be seen that the noise effect in cutting force signals is much less which can be explained by the smooth interaction between the natural diamond tool and workpiece material.

In order to analyse the influence of cutting edge radius, the thrust force and cutting force at about $110^{\circ}$ are extracted and compared as shown in Figure 11. The plot illustrates the plenty of influence of cutting edge radius on cutting forces. For tungsten carbide tool, the cutting force at feed rate of $0.5 \mu \mathrm{m} /$ tooth is almost the same with thrust force; whereas it is almost two times larger than thrust force for diamond tool. It can also be seen that both cutting force and thrust forces almost increase linearly with the increase of feed rate. The 
difference between cutting force and thrust force enlarges accordingly with the removed chip thickness increases. However, in term of the magnitude of cutting force and thrust force for two tools, it can be observed that the cutting force is about 3 times of thrust force for diamond tool; while the cutting force is only slightly higher than thrust force for tungsten carbide tool. Another fact to be noticed is that the difference of cutting force at the same feed rate by using these two tools is almost the same in varied feed rate. In addition, the change of cutting force is quite small along the feed rate increase. Whether this is pure coincidence or result of tool/material interaction needs further study.

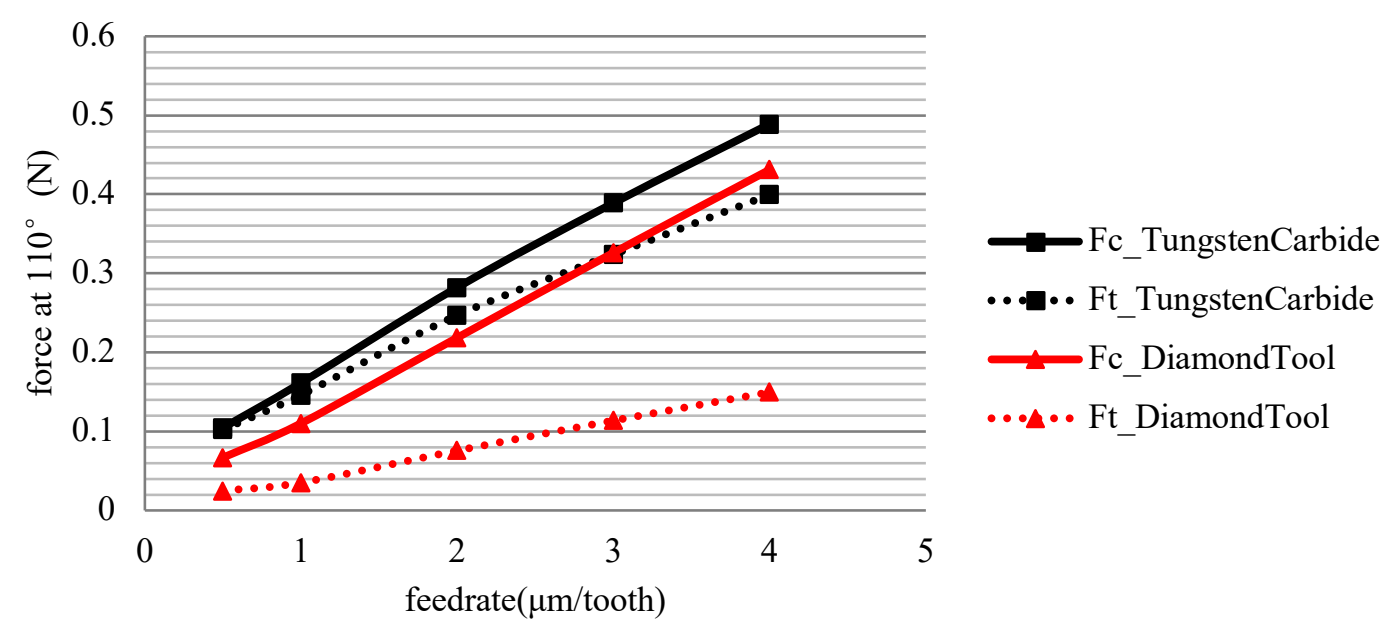

Figure 11 Cutting force and thrust force at $110^{\circ}$ by using two different tools versus the feed rate

(3) Chip formation mechanism and the minimum chip thickness in micro milling

From the results of simulations and experiments on precision turning ${ }^{[15]}$, it can be found that the minimum chip thickness can be down to around $15 \%$ of the cutting edge radius for tungsten carbide tools in machining aluminum6082-T6 material. Based on this finding and the measured cutting edge radius of tungsten carbide tool shown in Figure 2(d) used in micro-milling, it can be derived that the minimum chip thickness in this micro-milling process is around $0.21 \mu \mathrm{m}$. To verify its validity, experiments are carried out at the feed rate of $0.2 \mu \mathrm{m} /$ tooth. In fact, due to the periodic rotation of cutting tool, the chip thickness in each revolution changes from zero to the maximum and then reduces to zero again. Thus, the minimum chip thickness can be found in each revolution. A method based on the 
level of periodicity of cutting force at various feed rate to identify the minimum chip thickness is proposed by $\mathrm{Kim}^{[5]}$. From his research, it can be found that there is a local maximum in radial thrust force in micro-milling process during the non-cutting regime. The resultant thrust force at the feed rate of $0.2 \mu \mathrm{m} /$ tooth is shown in Figure 12. It can be found that the thrust force reaches the maximum (black circle) in every two revolutions. Considering the force variation, it can be illustrated that this is due to the high ploughing effect during the non-cutting regime. When chips are formed, the material shearing and fracture make the force more vibrant (green circle) and the peak value is smaller than the maximum during the ploughing.

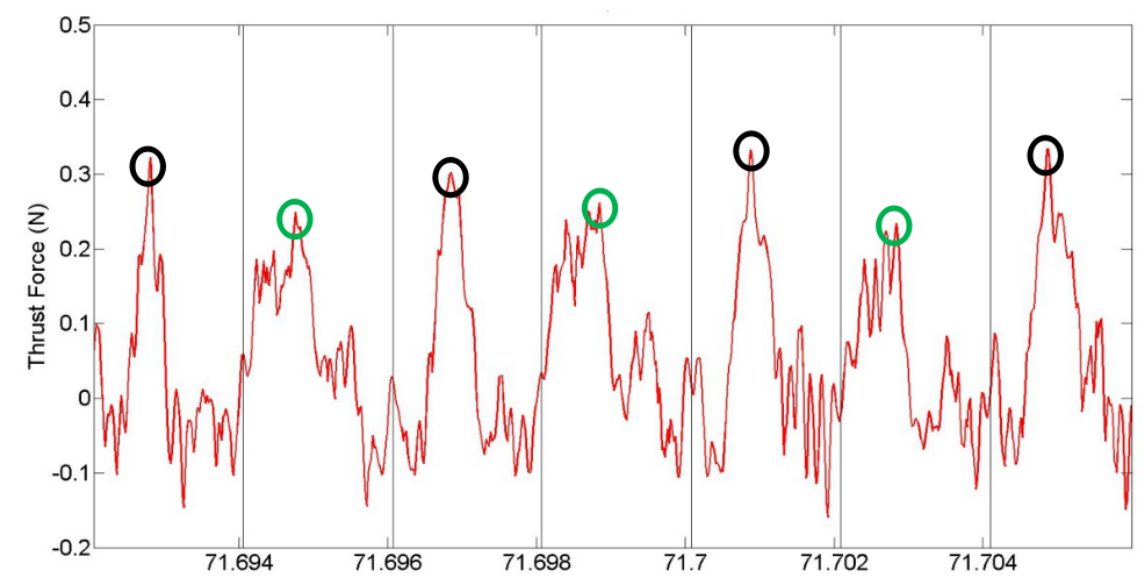

Figure 12 Thrust force at feed rate of $0.2 \mu \mathrm{m} /$ tooth by using tungsten carbide tool

The cutting force and thrust force at the uncut chip thickness of $0.2 \mu \mathrm{m}$ among consecutive revolutions are extracted from the full sequence by using MATLAB. Figure 13 shows the cutting force and thrust force fluctuate at the approximate frequency of every two revolutions. Taking this into consideration, it can be deduced that the minimum chip thickness is larger than $0.2 \mu \mathrm{m}$. 


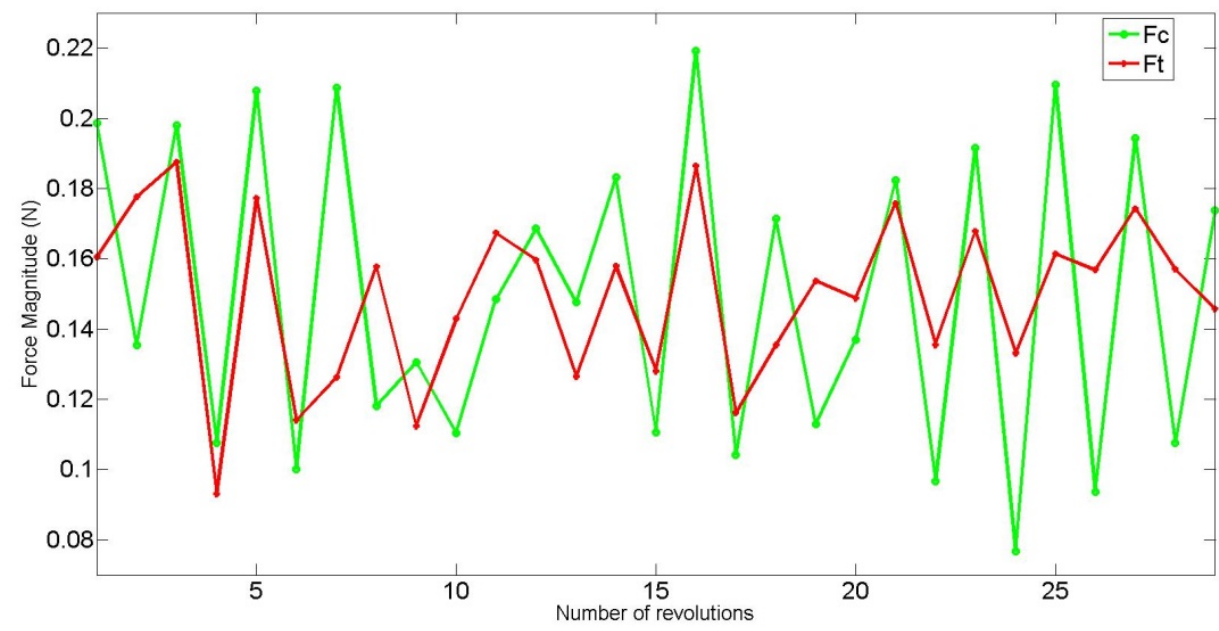

Figure 13 Cutting forces and thrust forces among consecutive revolutions by using a tungsten carbide tool

For the feed rate of $2 \mu \mathrm{m} /$ tooth, the uncut chip thickness reaches the peak of $2 \mu \mathrm{m}$ at position of $90^{\circ}$. Thus, at the position of $9^{\circ}$, the uncut chip thickness reaches the theoretical minimum chip thickness of $0.2 \mu \mathrm{m}$. The cutting force and thrust force under the feed rate of $2 \mu \mathrm{m} /$ tooth at position of $9^{\circ}$ in revolution is computed. The calculated uncut chip thickness is approximately $0.3 \mu \mathrm{m}$ by calculation with $2 \sin (\theta)$ in this cutting process. Figure 14 clearly reveals that the cutting force is much larger than thrust force, which means the chips are formed in every revolution. The fluctuation of both cutting force and thrust force is acceptable taking account of other influencing factors such as tool vibration, material inhomogeneity and feed velocity variation.

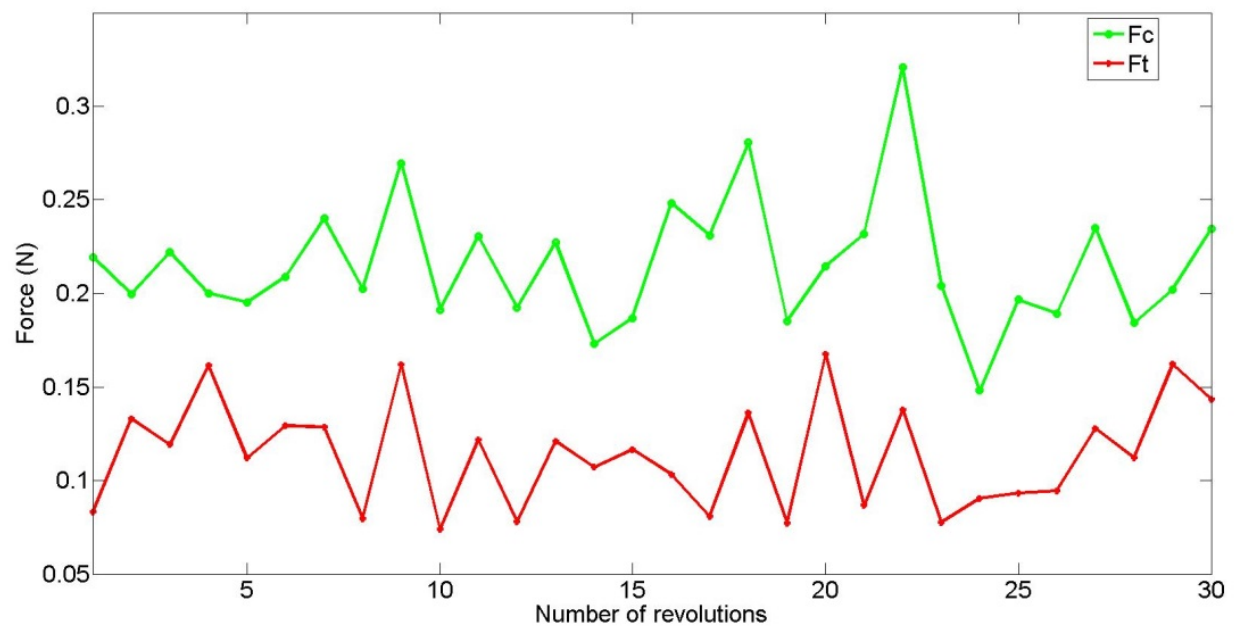

Figure 14 Extracted cutting force and thrust forces at $0.3 \mu \mathrm{m}$ chip thickness by using a tungsten carbide tool 
Combining the previous findings, it can be concluded that the minimum chip thickness for the micro milling on aluminum by using the tungsten carbide tool is approximately $0.2-0.3$ $\mu \mathrm{m}$. Therefore, the ratio of the minimum chip thickness to cutting edge radius $(1.4 \mu \mathrm{m})$ is around $14 \%-21 \%$, which is in good alignment with the findings obtained from precision turning simulations and experiments ${ }^{[10]}$. From the analysis of cutting force and chip morphology, it is found the chip formation and cutting force in micro milling need to be quantitatively analyzed at high precision. Introducing specific cutting force is essential, as it collectively reveals the effective force at unit area or volume, which leads to the chip formation and resultant surface generation. When the specific cutting force is larger than the Young's modulus of the workpiece material, it overcomes the ultimate strength of the workpiece material, and the chips are thus formed at this point. Due to the extreme sharpness of the cutting edge at diamond tools and the round cutting edge of tungsten carbide tool, the cutting forces by using tungsten carbide tool are much larger than using diamond tool with same machining parameters. This perfectly matches the concept of specific cutting force in micro milling. The specific cutting force concepts help provide an in-depth scientific understanding on chip formation mechanisms in micro milling process, particularly because the cutting forces are at the $0.1-1 \mathrm{~N}$ scale and difficult to be accurately measured. The concept, to some extent, also bridges the gap between the cutting forces and chip formation in micro milling.

\section{Conclusions}

In this paper, the chip formation process in micro milling aluminum 6082-T6 is investigated particularly with tungsten carbide and natural diamond micro milling tools, where the natural diamond tool is treated as perfectly sharp due to the extremely small cutting edge radius. The cutting force modelling using specific cutting force at the unit area is proposed, which helps establish a scientific understanding on the chip formation mechanisms in correlation with micro cutting forces in micro milling processes. Furthermore, the difference between the chip formation mechanisms in micro milling and 
conventional macro milling is investigated by using modelling and analysis supported with well-designed experimental trials. Both the analytical and experimental results illustrate that for using tungsten carbide tools, chips formation during consecutive revolutions is affected by the tool/material interfacial pair and the cutting edge radius jointly; whereas chips formation in using the natural diamond tool is intact and separate. Cutting forces are acquisition collected in experiment trials and the difference caused by the respective cutting edge radius of those two types of micro milling tools is quantitatively studied. It is found that the cutting force and thrust force are of the same order when the cutting edge radius cannot be ignored. For using the natural diamond tool with a sharp cutting edge, the cutting force is usually 2 times higher than the thrust force. The minimum chip thickness in micro milling is determined through both simulations and experimental cutting trials, the results are in good agreement.

\section{Acknowledgements}

The authors would like to thank the Korean Institute of Machinery and Materials (KIMM) for partially funding this research (Grant No. R31063) and helpful discussions with the project partners.

\section{Nomenclature}

$F_{x}(t), F_{y}(t) \quad$ Orthogonal cutting force and thrust force

$\mathrm{F}_{\text {Sx }}(\mathrm{t}, \mathrm{k}), \mathrm{F}_{\mathrm{Sy}}(\mathrm{t}, \mathrm{k}) \quad$ Specific cutting force and specific thrust force

$\mathrm{R} \quad$ Nominal radius of cutting tool

$\beta \quad$ Helix angle of cutting tools

$\theta_{\mathrm{en}} \quad$ Engage entry angle of cutting flute 


$\begin{array}{llc}\mathrm{K}_{\mathrm{rp}}, \mathrm{K}_{\mathrm{tp}} & \text { Ploughing coefficients in radial and tangential directions } & \left(\mathrm{N} / \mathrm{mm}^{2}\right) \\ \mathrm{K}_{\mathrm{re}}, \mathrm{K}_{\mathrm{te}} & \text { Edge constants in radial and tangential directions } & \left(\mathrm{N} / \mathrm{mm}^{2}\right) \\ \mathrm{K}_{\mathrm{rc}}, \mathrm{K}_{\mathrm{tc}} & \text { Cutting force coefficients in radial and tangential directions } & \left(\mathrm{N} / \mathrm{mm}^{2}\right) \\ h(\theta i(z)) & (\mu \mathrm{m}) \\ z & \text { Uncut chip thickness } & (\mu \mathrm{m}) \\ \mathrm{t} & \text { Axial height of flute } & (\mathrm{s}) \\ \mathrm{k} & \text { Time point of milling process }\end{array}$

\section{References}

(1) Koc M and Ozel T. Micro Manufacturing: Design and Manufacturing of Micro-Products. New Jersey: John Wiley \& Sons, 2011.

(2) Vogler MP, Liu X, Kapoor SG, Ehmann KF, et al. Development of meso-scale machine tool (mMT) systems. Technical Paper Society of Manufacturing Engineers 2002; MS 2002 (MS02-181):1-9.

(3) Vogler MP, DeVor RE and Kapoor SG. Microstructure-level force prediction model for micro-milling of multi-phase materials. J Manuf Sci Eng Trans ASME 2003; 125(2):202-209.

(4) Liu X, DeVor RE, Kapoor SG, et al. The mechanics of machining at the microscale: Assessment of the current state of the science. J Manuf Sci Eng Trans ASME 2004; 126(4):666-678.

(5) Weule H, Hüntrup V and Tritschle H. Micro-cutting of steel to meet new requirements in miniaturization. CIRP Ann Manuf Technol 2001; 50(1):61-64.

(6) Kim C, Mayor JR and Ni J. A static model of chip formation in microscale milling. Journal of Manufacturing Science and Engineering 2004; 126(4):710-718.

(7) Kang I, Kim J, Seo Y, et al. A mechanistic model of cutting force in the micro end milling process. J Mater Process Technol 2007; 187:250-255.

(8) Yuan ZJ, Zhou M and Dong S. Effect of diamond tool sharpness on minimum cutting thickness and cutting surface integrity in ultraprecision machining. J Materials Process Technology 1996; 62(4): 327-330. 
(9) Cheng K and Huo D. Micro Cutting: Fundamentals and Applications. John Wiley \& Sons, Chichester, 2013.

(10) Sawangsri W and Cheng K. An innovative approach to cutting force modelling in diamond turning and its correlation analysis with tool wear. Proc IMechE, Part B: Journal of Engineering Manufacture 2016; 230 (3):405-415.

(11) Jiao F. Investigation on micro-cutting mechanics with application to micro-milling. $\mathrm{PhD}$ Thesis, Brunel University London, UK, 2015.

(12) Jackson, Mark J and Morrell, Jonathan S. Machining with Nanomaterials. USA: Springer, 2015.

(13) Davim, Paulo J. Traditional Machining Processes: Research Advances. Berlin Heidelberg: Springer, 2014.

(14) Abe T and Tsuruta T. Advances in Engineering Plasticity and its Applications. Elsevier, 2012.

(15) Huo D and Cheng K. An experimental investigation on micro milling of OFHC copper using tungsten carbide, CVD and single crystal diamond micro tools. Proceedings of the IMechE, Part B: Journal of Engineering Manufacture 2010; 224(B6):995-1003.

(16) Özel T and Dhanorker A. Meso/micro scale milling for micro-manufacturing. J. Mechatronics and Manufacturing Systems 2008; 1:23-42.

(17) Liu Z, Shi Z and Wan Y. Definition and determination of the minimum uncut chip thickness of micro cutting. The International Journal of Advanced Manufacturing Technology 2013; 69(5):1219-1232. 